\title{
How interacting pathways are regulated by miRNAs in breast cancer subtypes
}

\author{
Claudia Cava ${ }^{1}$, Antonio Colaprico ${ }^{2,3}$, Gloria Bertoli', Gianluca Bontempi ${ }^{2,3}$, Giancarlo Mauri ${ }^{4}$ \\ and Isabella Castiglioni ${ }^{*}$
}

From Twelfth Annual Meeting of the Italian Society of Bioinformatics (BITS)

Milan, Italy. 3-5 June 2015

\begin{abstract}
Background: An important challenge in cancer biology is to understand the complex aspects of the disease. It is increasingly evident that genes are not isolated from each other and the comprehension of how different genes are related to each other could explain biological mechanisms causing diseases. Biological pathways are important tools to reveal gene interaction and reduce the large number of genes to be studied by partitioning it into smaller paths. Furthermore, recent scientific evidence has proven that a combination of pathways, instead than a single element of the pathway or a single pathway, could be responsible for pathological changes in a cell.

Results: In this paper we develop a new method that can reveal miRNAs able to regulate, in a coordinated way, networks of gene pathways. We applied the method to subtypes of breast cancer. The basic idea is the identification of pathways significantly enriched with differentially expressed genes among the different breast cancer subtypes and normal tissue. Looking at the pairs of pathways that were found to be functionally related, we created a network of dependent pathways and we focused on identifying miRNAs that could act as miRNA drivers in a coordinated regulation process.
\end{abstract}

Conclusions: Our approach enables miRNAs identification that could have an important role in the development of breast cancer.

Keywords: miRNAs, Pathway cross-talk, Breast cancer, Network of pathways

Abbreviations: AUC, Area under the curve; BC, Breast cancer; HER2, Human epidermal growth factor receptor 2; IPA, Ingenuity pathway analysis; MI, Mutual Information; miR-r, miRNAs regulating; NGS, Next generation sequencing; NS, Normal samples

\section{Background}

The identification of breast cancer $(\mathrm{BC})$ gene signatures based on morphology (stage and grade) and two key markers, estrogen receptor (ER) and human epidermal growth factor receptor 2 (HER2), are a challenge for current clinical practice [1-5].

However, the landscape of alterations in $\mathrm{BC}$ is more complex and heterogeneous. With the introduction of gene expression microarrays and next generation

\footnotetext{
* Correspondence: isabella.castiglioni@ibfm.cnr.it

${ }^{1}$ Institute of Molecular Bioimaging and Physiology (IBFM), National Research Council (CNR), Milan, Italy

Full list of author information is available at the end of the article
}

sequencing (NGS), additional studies on the molecular classification of $\mathrm{BC}$ were carried out. These have led to the identification of four molecular subtypes associated with distinct characteristics, distinct genetic mechanisms of disease and differences in patient survival [6, 7]: Luminal A, Luminal B, Triple Negative/Basal like and HER2 subtypes [6].

By expression profiling, the large majority of ER+ and/ or progesterone receptor PgR+ tumours are "luminal subtypes" [8, 9]: Luminal A and Luminal B; they have a relatively good prognosis with the former being typically low grade $[10,11]$. Luminal $A$ is the most common subtype and represents $50 \%-60 \%$ of all $\mathrm{BC}$ and typically 
highly expresses regulated gene SLC39A6 (solute carrier family 39 (zinc transporter), member 6), transcription factors GATA3, FOXA1 and XBP1, and luminal cytokeratins KRT8 and KRT18 [12,13]. Luminal B comprises $15 \%-20 \%$ of $\mathrm{BC}$ and has a more aggressive phenotype and lower survival rates after relapse [14-17]. It shows an increased expression of proliferation-related genes such as avian myeloblastosis viral oncogene homolog $(v-M Y B)$, gamma glutamyl hydrolase $(G G H)$, lysosome-associated transmembrane protein 4-beta (LAPTMB4), nuclease sensitive element binding protein 1 (NSEP1) and cyclin E1 (CCNE1) [18].

For a successful discrimination of luminal-B tumours from luminal- $A$ in clinical practice, Cheang et al. [8] suggested an immunohistochemistry proliferation marker, the Ki67 hormone receptor. The authors determined the Ki67 cut off point (14\%) that discriminates luminal-A from luminal-B tumours. However, Ki67 immunohistochemistry shows some limitations, such as low intra- and inter-laboratory reproducibility, the arbitrary selection of standard antibodies for testing, in addition to potential problems resulting from tumour heterogeneity [9].

Concerning the response to therapy of $\mathrm{BC}$ subtypes, Luminal B responds better to neoadjuvant chemotherapy, but is less responsive to hormonal therapy than Luminal A [9]. Potential targets in Luminal B are insulin-like growth factor 1 (IGF-1) signalling, fibroblast growth factor $(F G F)$ signalling, Phosphoinositide 3-kinase signalling (PI3K) [19].

The interplay between ER and insulin-like growth factor 1 receptor $(I G F-1 R)$ shows a critical role in tamoxifen resistance. High circulating plasma levels of IGF-1, a ligand for IGF-1R, are detected in women with an increased risk of relapse on adjuvant tamoxifen [20].

Several studies indicate that the FGF factor, involved in angiogenesis [21, 22], and its receptor FGFR1 are amplified in cells resistant to endocrine therapy [23, 24]. Knockdown of FGFR1 and/or the use of a small molecule FGFR tyrosine kinase inhibitor could reverse resistance to endocrine therapy [23, 24].

Several methods to interrupt IGF-1 signalling, FGF signalling, and PI3K have been proposed [19, 25, 26]. Creighton et al. [27] suggested that the combined effect of endocrine therapy luminal-B BC cell lines and PI3K inhibitor could increase growth inhibition induced by the only endocrine therapy. Atzori et al. [26] developed antibodies against IGF-1R that block IGF-1 ligandmediated activation and small-molecule inhibitors of the IGF-1R tyrosine kinase domain.

Some antibodies and small-molecule inhibitors against FGFR are currently in clinical testing, such as TKI-259 single agent, and Exemestane [27]. Agents targeting the PI3K pathway comprise rapamycin analogues or mTOR inhibitors [27].
The basal-like subtype, one of the most clinically aggressive groups among the different subtypes, represents $8 \%-37 \%$ of all $\mathrm{BC}$, and is the one with highest rate of metastasis to the brain and lung [28]. It is more commonly negative for all 3 markers-ER, PgR, and HER2-the "triple-negative" phenotypic classification [16].

There are several other biomarkers associated with the basal subtype as well as putative candidates suitable for immunohistochemical screening [29-31].

An association between the basal subtype and germline mutations in the BRCA1 gene, often termed the "caretaker of the genome", has been well described, and it may be speculated that both inherent DNA damagesensing processes and DNA repair mechanisms are central in the development of basal-like tumours [29-31]. However, currently, there is no specific international agreement on complementary biomarkers that can define basal-like cancers [32].

Given the lack of validated molecular targets in basal $\mathrm{BC}$, conventional chemotherapy has been the only therapeutic option for women with this kind of tumour [33]. Based on BRCA1 mutations, some studies explored the use of platinum chemotherapy agents (carboplatin, cisplatin, and others) [33]. Antiangiogenic therapies targeting $V E G F$ and its receptors have emerged as promising therapies given the evidence of aberrant VEGF pathway activation in basal BC [34]. Moreover, small-molecule and antibody-based EGFR inhibitors are also explored as targeted therapies [35].

HER2-positive (HER2+) cancer represents $15-20 \%$ of $\mathrm{BC}$ subtypes. HER2+ confers more aggressive biological and clinical behaviour [36]. These tumours present a high expression of the HER2 gene and of other genes associated with the HER2 pathway [37].

Currently, the treatment in advanced HER2+ BC is the combination of trastuzumab, pertuzumab, and the chemotherapy agent taxane [37]. High expression of HER2 promotes tamoxifen resistance and the addition of trastuzumab could improve the tamoxifen response [38].

This $\mathrm{BC}$ variety has consequences in the diverse clinical behaviour and provides critical insight for the development of personalized therapies.

However, gene expression microarrays and NGS data have many more genes than number of samples, and methods to reduce the dimension of genes in functional units, such as gene sets, pathways, and network modules, have been recently explored [39, 40]. These aggregation methods are based on the statement that the set of genes involved in the same biological processes are often collaborative in the development and progression of $\mathrm{BC}$, and show an easier interpretation of the underlying biology $[41,42]$.

Methodologies to identify the set of genes enriched from a genetic signature whose combined expression 
pattern is that uniquely characteristic of a given phenotype are promising approaches.

Alterations of the interplay among pathways leading to uncontrolled cellular proliferation, survival, invasion, and metastases are hallmarks of the $\mathrm{BC}$ process.

The mitogen activated protein kinase (MAPK), phosphatidylinositol 3-kinase (PI3K), Akt and nuclear factor kappa B (NF-kB) are commonly de-regulated in different BC subtypes [36]. Raf/mitogen-activated and extracellular signal-regulated kinase (MEK)/extracellular signalregulated kinase (ERK) are critical for normal human physiology, and also commonly dysregulated in several human cancers, including BC [43].

Saini et al. [43] suggested, both in vitro and in vivo, that PI3K/AKT/mTOR and Raf/MEK/ERK cascades are interconnected and the inhibition of one pathway can still result in a deregulation of the other. Notch signalling pathway is associated with many oncogenic signalling pathways, such as developmental signals, i.e., Wnt and Hedgehog signalling, growth and transcriptional factors, cytokines, and oncogenic kinases [44]. A review [45] examined the molecular basis of the collaboration and integration of the ER, and MAPK.

Currently, two main approaches have been proposed to identify functional units deregulated in a disease. One approach is to identify de novo functional units from the data. Following this approach, van Vliet proposed an unsupervised method to identify gene patterns using a score applied to a Bayes classifier [46]. Ma et al. [47] used weighted co expression networks and their module to describe the collaboration among genes.

The other main approaches used existing functional units to build prognostic or diagnostic analysis. Abraham et al. proposed features derived from pre-specified gene sets from the Molecular Signatures Database (MSigDB), and, by using a statistical test aggregating the expression levels of all genes within a set, they derived prognostic gene sets [48]. Huang et al. [40] proposed a new pathwaybased de-regulation scoring matrix transforming the gene features in combination with Cox regression and L1LASSO regularization to model survivals. A genomic model consisting of fifteen cancer relevant pathways was revealed and validated on three independent BCs.

Deregulation of signalling events in a given cancer sample is of great clinical interest in order to identify candidate drugs developed to specifically modulate upstream signalling events [49]. Recent progress in cancer biology has revealed that miRNAs are potential therapeutic targets suggesting the introduction of the miRNA mimic oligonucleotides in Phase I cancer clinical trials.

Oncogenic or tumour suppressive miRNAs have been implicated in the regulation of central cellular pathways, such as differentiation and apoptosis, across several tumour types [50], but the discovery of how a miRNA regulates its targets in tumour samples is still challenging. Recent studies revealed, for instance, that $\mathrm{Hsa}$ $m i R-21$ is up regulated in $\mathrm{BC}$ [51], while Hsa-miR-335 and $H s a-m i R-200 c$ have been shown to inhibit metastatic cell invasion [52].

Emerging evidence demonstrates that miRNAs play an essential role in controlling stem cell properties by regulating, for instance, epithelial to mesenchymal transition (EMT) [53]. EMT has a fundamental role in cancer cells with the loss of intracellular junctions and epithelial polarity. Several miRNAs, such as Hsa-let-7, Hsa-miR-10, HsamiR-34, Hsa-miR-200, and Hsa-miR-205 are described as regulator of this process [53].

Other miRNAs have been reported to have an active role in tumour proliferation control. Hsa-miR-92a can promote tumour proliferation by controlling the PI3K/ Akt/mTOR pathway [54]. Several other miRNAs were found to be up-regulated in $\mathrm{BC}$; these include the $\mathrm{Hsa}$ miR-221/222 cluster [55], Hsa-miR-9, Hsa-miR10b, Hsa-miR-29a, Hsa-miR-96, Hsa-miR-146a, Hsa-miR181, Hsa-miR-373, Hsa-miR-375, Hsa-miR-520c, and Hsa-miR589 [56], suggesting their potential use for BC diagnosis, prognosis, and therapeutic studies $[55,56]$.

All these findings demonstrate the ability of miRNAs to regulate the development of malignancies modulating critical cancer-related genes and signalling pathways.

While many studies demonstrated the role of miRNAtarget interactions in a single pathway, there are little evidence on the interaction of specific miRNAs with genes of different pathways.

Hsa-miR-125, whose expression correlates with the HER2 status [57], has been shown to be significantly down regulated in BC [58]. Experimentally, the overexpression of Hsa-miR-125 decreases the expression level of $E R B B 2$ and $E R B B 3$, reducing cell motility and invasiveness of numerous cancers, including $B C$ [59]. The Let-7 regulatory network suppresses metastasis acting on the chromatin-remodelling protein HMGA2 and the transcription factor $B A C H 1$ [60]. Both targets promote the transcription of pro-invasive genes that regulate cell invasion and metastasis to the bone [60].

Another important miRNA in BC is Hsa-miR-206. It has been found to be down-regulated in ER $\alpha$-positive $\mathrm{BC}$, both in patient samples and $\mathrm{BC}$ cell lines [61], and in lymph node metastatic BC [62]. A critical role of $\mathrm{Hsa}$ miR-206 has been recently demonstrated in the regulation of the 3' UTR of cyclin D1, inducing G1 arrest and a decrease in cell proliferation in BC cells [63], thus suggesting a potential role as a tumour suppressor. It has been also shown that $H s a-m i R-206$ regulates $\mathrm{ER} \alpha$ via interaction with its 3' UTR [64], demonstrating a specific function in most aggressive types of BC.

In this work we developed a method to detect miRNAs regulating pathway interactions, based on the integration 
of gene expression profiles and biological pathways and miRNAs. We validated the approach in BC subtypes, obtaining, for each BC subtype, a network of pathways enriched from differentially expressed genes. We focused on the pairs of pathways able to differentiate a particular $\mathrm{BC}$ subtype with respect to the normal type. miRNAs significantly enriched from their gene targets in at least two pathways were found to be key regulators of interacting pathways.

\section{Methods}

\section{Breast cancer subtypes}

In our study we focused on four different $B C$ subtypes: luminal A, luminal B, basal, and HER2 which we compared with normal samples (NS). We considered the expression level of mRNAs and miRNAs extracted from a TCGA BC data set. We performed a quantile analysis on TCGA miRNAs and mRNA, in order to exclude genes and miRNAs with a small variance, thus obtaining 1046 miRNAs and of 15243 genes. We then used BC matched samples miRNA-mRNA for all the subsequent analyses.

\section{Luminal $A$ vs. NS}

We used 233 BC luminal A samples and 113 NS for mRNA analysis, and 233 BC luminal A samples and 87 NS for miRNA analysis.

\section{Luminal B vs. NS}

We used 103 BC luminal B samples and 113 NS for mRNA analysis, and $103 \mathrm{BC}$ luminal A samples and 87 NS for miRNA analysis.

\section{Basal vs. NS}

We used 74 BC Basal samples and 113 NS for mRNA analysis, and 74 BC Basal samples and 87 NS samples for miRNA analysis.

\section{HER2 vs. NS}

We used from 43 BC HER2 samples and 113 NS for mRNA analysis, and 43 BC HER2 samples and 87 NS for miRNA analysis.

\section{Grouping and bootstrapping analysis}

We performed an analysis based on several boots, with each boot consisting of four steps and working on different (randomly selected) training and testing data sets.

In order to perform bootstrapping, we implemented a classifier based on Monte Carlo cross validation, that randomly splits a part of the original data in the training data set (60\% in our case) and the rest of original data in the testing set (40\% in our case). The first, second and third step are performed on the training data set, the fourth step both on the training and testing data set.
In order to avoid problems of unbalanced classes of $\mathrm{BC}$ and NS, we randomly selected classes with the same number of $\mathrm{BC}$ and $\mathrm{NS}$ in both the training and testing dataset.

\section{Differentially expressed genes: 1 st step}

Differentially expressed genes between each subtype class of BC samples and class of NS were identified by statistical analysis using the function TCGAanalyze DEA from the package TCGAbiolinks from Bioconductor. The following parameters were used: quantile-adjusted conditional maximum likelihood, abs(log fold change) $>1$, and FDR $<0.01$ [65]. The obtained $p$-values were adjusted by using the Benjamin-Hochberg procedure for multiple testing correction [66].

\section{Pathways enriched from differentially expressed genes: 2nd step}

Given 589 pathways derived from the Ingenuity Pathway Analysis (IPA) database, a pathway enrichment analysis was applied. The enrichment was evaluated using the Fisher's Exact Test between differentially expressed genes and IPA pathways. We considered a pathway to be enriched if $p$-value was $<0.01$.

\section{Interacting pathways: 3rd step}

Interactions among the enriched pathways were quantified by an interaction score (IS), defined as:

$$
\mathrm{IS}=\left|\left(\mathrm{M}_{\mathrm{x}}-\mathrm{M}_{\mathrm{y}}\right)\right| /\left(\mathrm{S}_{\mathrm{x}}+\mathrm{S}_{\mathrm{y}}\right)
$$

where $M_{X}, S_{X}, M_{Y}$ and $S_{Y}$ represent the mean and the standard deviation of expression levels of genes in pathways $\mathrm{X}$ and $\mathrm{Y}$, respectively. Maximum cross-talk was found for IS near 0.

For every comparison (BC subtype vs NS), we obtained a matrix of IS, with each raw corresponding to each $\mathrm{BC}$ sample and each column corresponding to IS related to each pair of significantly enriched pathways.

\section{Identification of the best pathways for breast cancer subtype classification: 4th step}

For every comparison (BC subtype vs NS), for the training data set, we used the matrix of IS to classify the class of BC samples and NS. We used Random Forest algorithm (RF) from the R-package [67], setting the following parameters: number of variables randomly sampled at each $\operatorname{split}=\operatorname{sqrt}(\mathrm{p})$, $\mathrm{p}$ being the number of variables in the matrix of data; and the number of trees grown $=500$. In order to validate the classifier, we used a k-fold cross-validation ( $\mathrm{k}=10$ except in case of HER2 vs. normal samples, given the reduced number of samples we used $k=5$ ) obtaining Area Under the Curve (AUC). 
We thus selected the 10 pairwise pathways with the best AUC in the classification of the different BC subtypes vs NS.

We finally validated the classification using the top 10 pairwise pathways and the same k-fold cross-validation on the testing data set in terms of AUC.

The four steps described above were repeated multiple times (50 bootstraps).

Specifically, each bootstrap generated from a training dataset i) 1 step: a list of differentially expressed genes, ii) 2 step: a list of pathways significantly enriched by differently expressed genes, iii) 3 step: a subtype-specific matrix of IS for each pair of pathways significantly enriched, and iii) 4 step: the top 10 pairwise pathways with the best AUC performance.

In conclusion, for each subtype and for all 50 bootstraps, we obtained the $10 \times 50(=500)$ pairwise pathways with the best AUCs., from which we selected, by ranking their frequency, the top 10 pairwise pathways.

\section{miRNAs regulating the top 10 pairwise pathways}

Mutual Information (MI) was applied between the dataset of 1046 miRNAs and 15243 genes, providing a linking index between miRNAs and genes. MI was calculated using entropy estimates from K-nearest neighbour distances [68] with the R-package parmigene [69]. In this step we obtained a list of candidate target genes for each miRNA.
In order to link miRNAs with the top 10 pairs of pathways, we applied a Fisher's Exact Test between candidate target genes (as obtained from MI) and genes within each pairwise pathway (when $p$-value $<0.01$ in both pathways). We thus identified a group of miRNAs regulating the top 10 pairwise pathways (miR-r). Then, we focused only on those miR-r differentially expressed between each BC subtype and NS (quantile-adjusted conditional maximum likelihood, $p$-values adjusted using the Benjamin-Hochberg procedure for multiple testing correction [66]). Figure 1 shows the proposed procedure.

\section{Results}

Luminal A vs. NS

After 50 bootstraps, among the $50 \times 10=500$ pairwise pathways, we found 157 pairwise pathways enriched with 4703 differentially expressed genes. Indeed, many pathways were found in common among the 10 top pairs in many bootstraps.

The final top 10 pairwise pathways, selected according to their frequency in the top 10 in all bootstraps from the 157 pairwise pathways, are shown in Table 1.

Figure 2 shows a boxplot with the AUC values for the final 10 pairwise pathways in both the training and testing phase. Both AUC values are good (median >90 \%), although the performance of training is better.

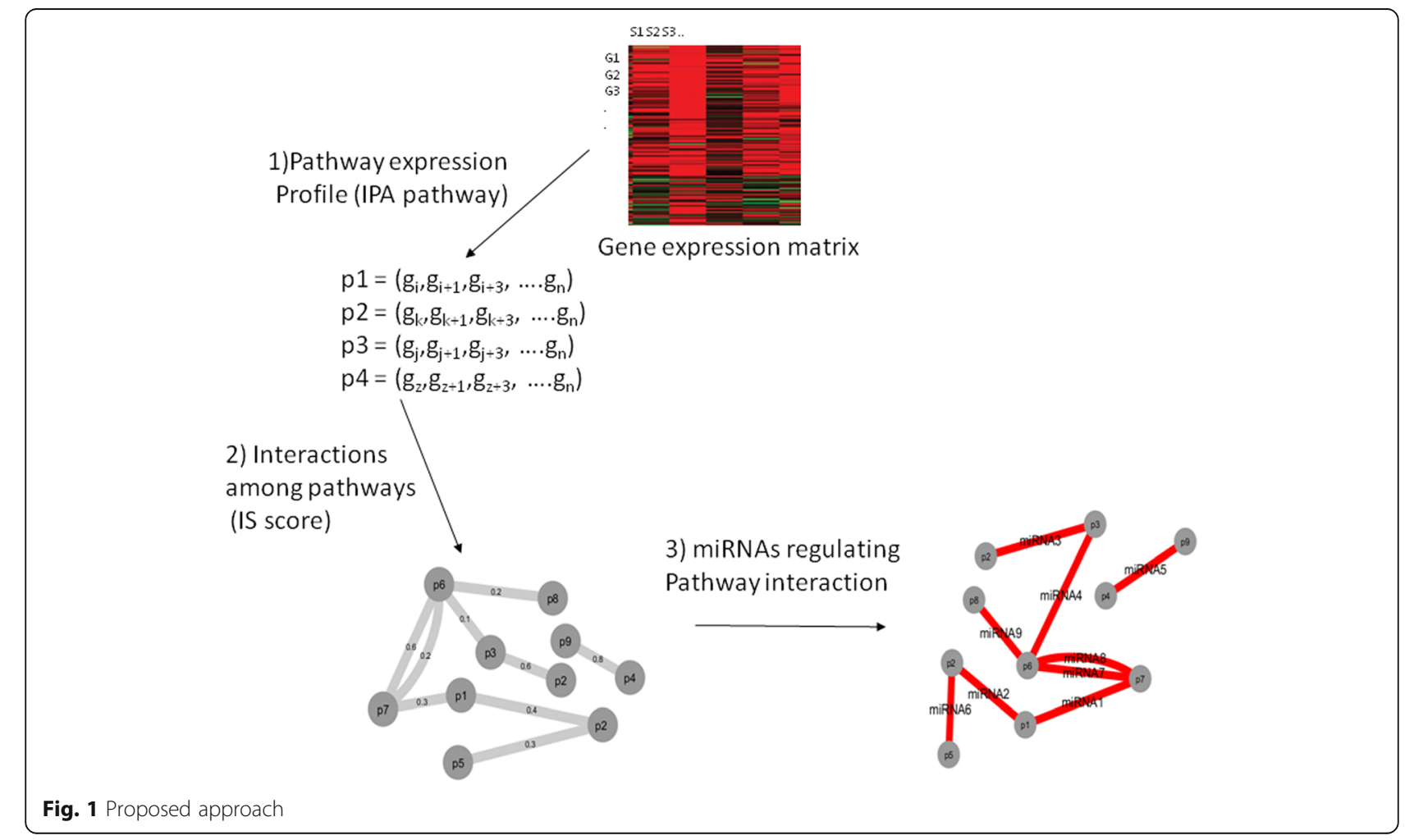


Table 1 Luminal A: frequency of pairwise pathways in the top 10 positions for all 50 bootstraps

\begin{tabular}{|c|c|}
\hline Pairwise pathway & Frequency \\
\hline 1) Ethanol Degradation IV;Glioma Invasiveness Signalling & $31 / 50$ \\
\hline $\begin{array}{l}\text { 2) Intrinsic Prothrombin Activation Pathway; Extrinsic } \\
\text { Prothrombin Activation Pathway }\end{array}$ & $28 / 50$ \\
\hline 3) Ethanol Degradation IV;Estrogen Receptor Signalling & $25 / 50$ \\
\hline $\begin{array}{l}\text { 4) Axonal Guidance Signalling; Acute Phase } \\
\text { Response Signalling }\end{array}$ & $17 / 50$ \\
\hline $\begin{array}{l}\text { 5) Ethanol Degradation IV;Regulation of Cellular Mechanics } \\
\text { by Calpain Protease }\end{array}$ & $16 / 50$ \\
\hline 6) Glioma Invasiveness Signalling; Dopamine Degradation & $15 / 50$ \\
\hline 7) Glioma Invasiveness Signalling; Fatty Acid oxidation & $12 / 50$ \\
\hline $\begin{array}{l}\text { 8) Glioma Invasiveness Signalling; Tryptophan } \\
\text { Degradation X (Mammalian, via Tryptamine) }\end{array}$ & $12 / 50$ \\
\hline 9) Acute Phase Response Signalling; HIF1 Signalling & $11 / 50$ \\
\hline $\begin{array}{l}\text { 10) Glioma Invasiveness Signalling; Oxidative Ethanol } \\
\text { Degradation III }\end{array}$ & $10 / 50$ \\
\hline 11) Axonal Guidance Signalling; Gs Signalling & $9 / 50$ \\
\hline 12) HIF1 Signalling; Fatty Acid-oxidation & $9 / 50$ \\
\hline $\begin{array}{l}\text { 13) Oxidative Ethanol Degradation III; Estrogen Receptor } \\
\text { Signalling }\end{array}$ & $9 / 50$ \\
\hline 14) Retinoate Biosynthesis l; Estrogen Receptor Signalling & $8 / 50$ \\
\hline $\begin{array}{l}\text { 15) Tryptophan Degradation X (Mammalian, via Tryptamine); } \\
\text { Glioma Invasiveness Signalling }\end{array}$ & $8 / 50$ \\
\hline 50) $\ldots$ & $1 / 50$ \\
\hline
\end{tabular}

Dots indicate the other pairs of pathways with minor frequency
Figure 3 shows, for each bootstrap, the AUC of the top 10 pairs of pathways. We can see that some pairwise pathways (e.g. Ethanol Degradation IV; Glioma Invasiveness Signalling, Intrinsic Prothrombin Activation Pathway; Extrinsic Prothrombin Activation Pathway) have excellent AUC in most bootstraps.

Figure 4 shows the inter-pathway coordination among the final top 10 pairwise pathways in luminal A. Among pathways, the role of Glioma Invasiveness Signalling, hub of a network linking Tryptophan Degradation X (Mammalian, via Tryptamine), Ethanol Degradation IV, Dopamine Deregulation, Oxidative Ethanol Degradation III, and Fatty Acid-oxidation appears dominant.

We found six pairwise pathways with 11 significant miRNA regulators: 1) Acute Phase Response Signalling; HIF1 Signalling, 2) Axonal Guidance Signalling; Acute Phase Response Signalling 3) Ethanol Degradation IV; Glioma Invasiveness Signalling, 4) Ethanol Degradation IV; Estrogen Receptor Signalling 5) Glioma Invasiveness Signalling; Oxidative Ethanol Degradation III, and 6) Extrinsic Prothrombin Activation; Intrinsic Prothrombin Activation. Four pairwise pathways were not significantly deregulated by any miRNA.

Table 2 lists, for each of the six above mentioned pairwise pathways, their miRNA-r regulators with, their expression levels in BC luminal A and in NS, and the statistical significance of the comparison (in terms of log Fold Change).

The results of the MI analysis for the identification of candidate genes target of miRNAs are shown in the Additional file 1.

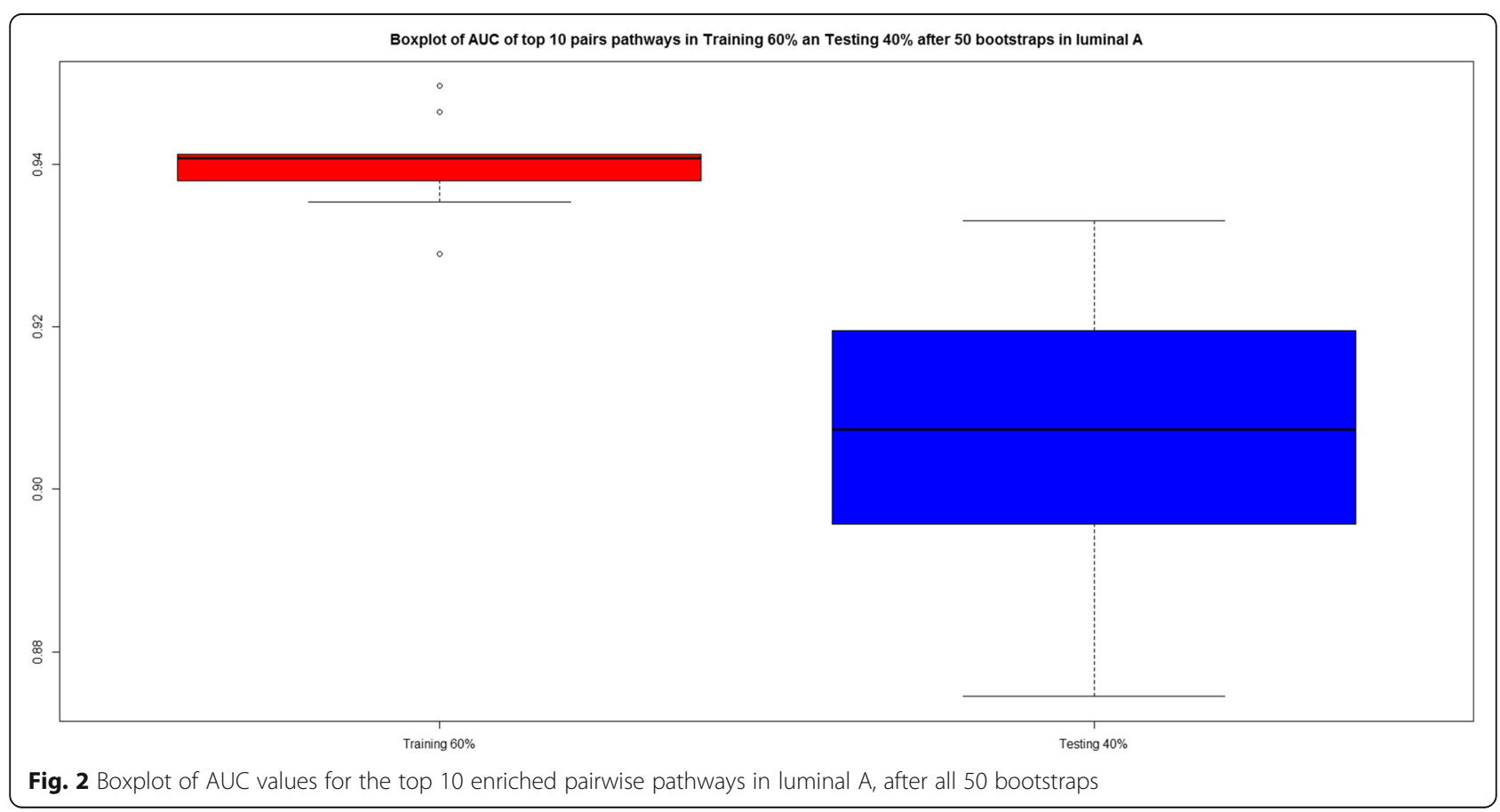




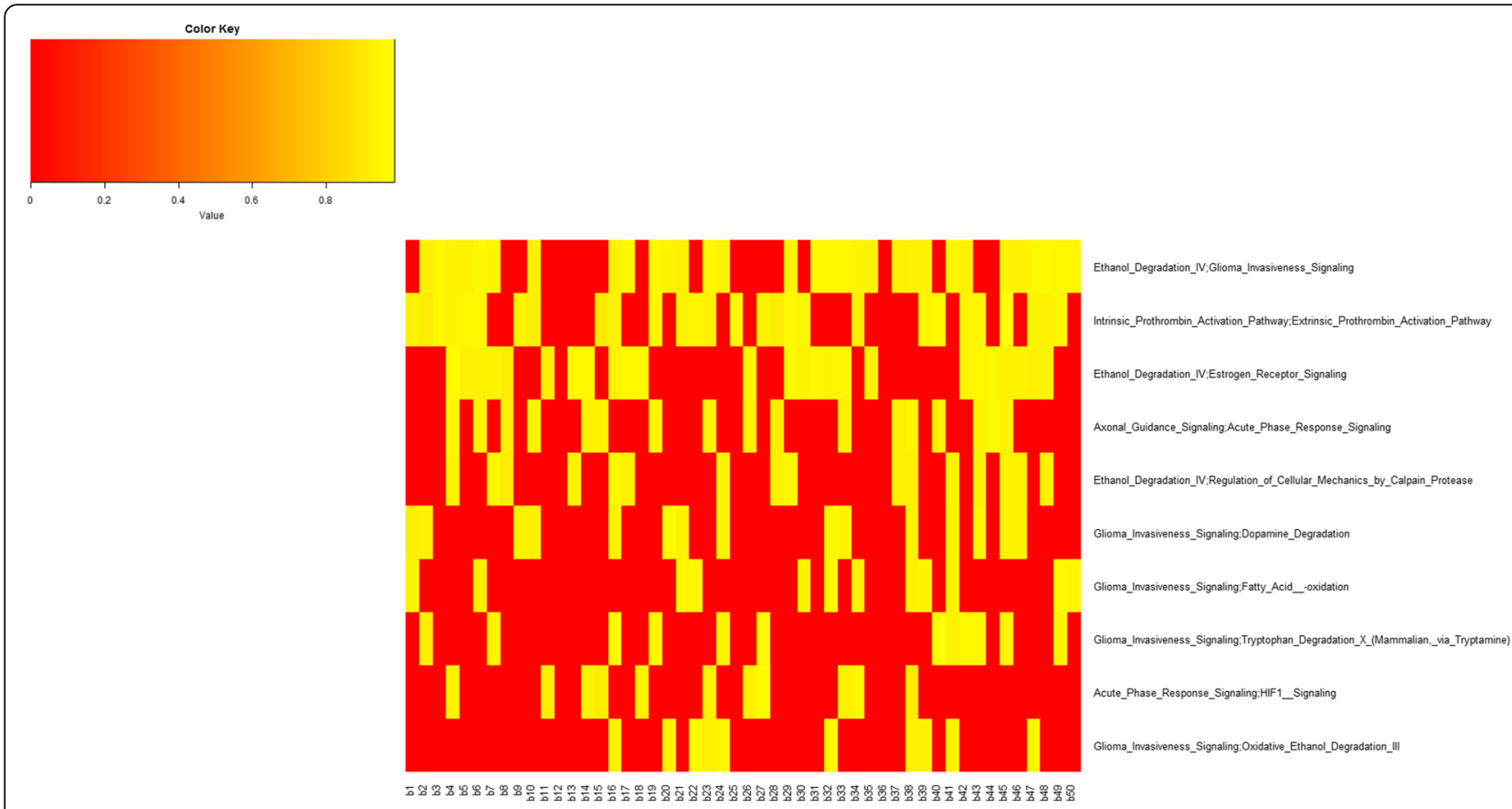

Fig. 3 AUC values representation with the top 10 pairwise pathways for all 50 bootstraps in luminal A. Yellow square indicates AUC values when the pairwise pathway was included in the top 10 for the corresponding bootstrap. Red square indicates that the pairwise pathways was not present in top 10 for that bootstrap

\section{Luminal B vs. Normal}

After 50 bootstraps, we found 129 pairwise pathways enriched with 5590 differentially expressed genes. Similarly to Luminal A. Many pathways were found in common among the top 10 pairs in many bootstraps.

The final top 10 pairwise pathways selected according to their frequency in the top 10 in all bootstraps from the 129 pairwise pathways, are shown in Table 3.
Figure 5 shows a boxplot with the AUC values for the final 10 pairwise pathways in both the training and testing phase, confirming the good AUC (median >95\%) both for training and testing.

Figure 6 shows, for each bootstrap, the AUC of the top 10 pairs of pathways. We can see that some pairwise pathways (e.g. Wnt/ -catenin Signalling; Mitotic Roles of Polo-Like Kinase and Epithelial Adherens Junction

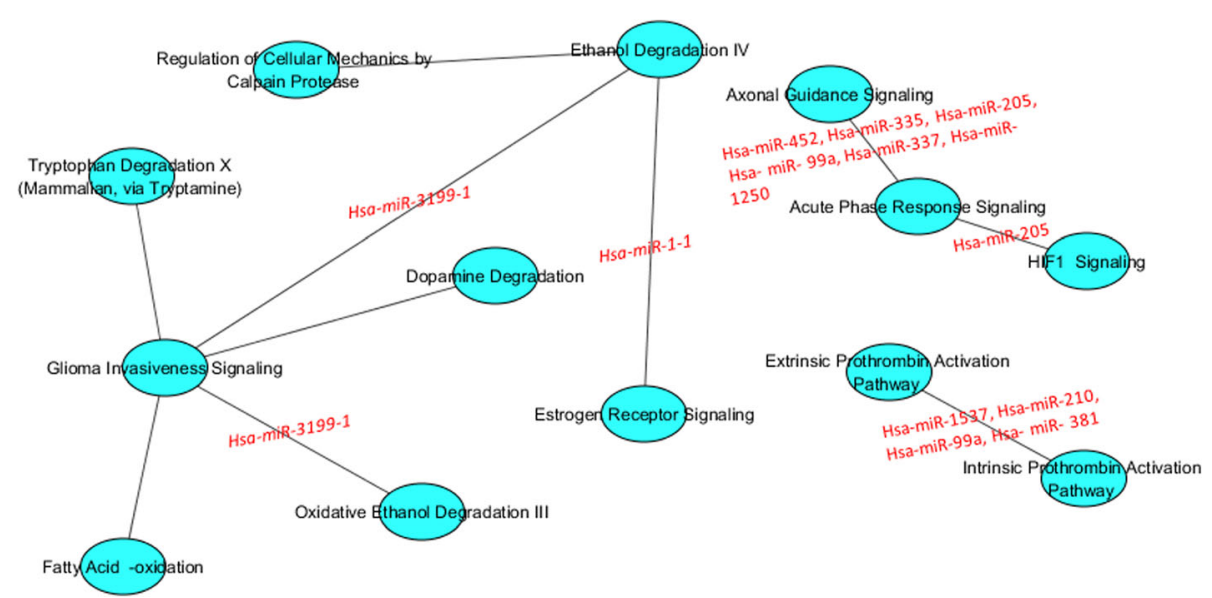

Fig. 4 Interaction of the top 10 pairwise pathways in luminal and their miRNA-r in BC luminal A 
Table 2 For each top 6 pairwise pathway in luminal A: miRNA regulators of pathways, their expression levels in BC and in NS, and the statistical significance of the comparison (in terms of log Fold Change)

\begin{tabular}{lllll}
\hline Pairwise pathways & miRNA-r & miRNA-r Exp. in BC & miRNA-r Exp. in NS & Statistical significance (log Fold Change) \\
\hline $\begin{array}{l}\text { 1. a) Acute Phase Response Signalling; } \\
\text { b) HIF1 Signalling }\end{array}$ & Hsa-miR-205 & 13006.16 & 25001.9 & -1.01017 \\
2. a) Axonal Guidance Signalling; & Hsa-miR-452 & 101.1974 & & \\
b) Acute Phase Response Signalling & Hsa-miR-335 & 333.4506 & 720.023 & -3.08782 \\
& Hsa-miR-205 & 13006.16 & 1391.644 & -2.27528 \\
& Hsa-miR-99a & 4268.871 & 1001.9 & -1.01017 \\
& Hsa-miR-337 & 208.6352 & -1.71181 \\
& Hsa-miR-1250 & 0.746781 & 547.3908 & -1.57547 \\
3. a) Ethanol Degradation IV; & Hsa-miR-3199-1 & 1.793991 & 0.103448 & 1.636118 \\
b) Glioma Invasiveness Signalling & & & 5.45977 & -1.79743 \\
4. a) Ethanol Degradation IV; & Hsa-miR-1-1 & 0.021459 & & \\
b) Estrogen Receptor Signalling & & & 1.62069 & -3.82055 \\
5. a) Glioma Invasiveness Signalling; & Hsa-miR-3199-1 & 1.793991 & & \\
b) Oxidative Ethanol Degradation III & & 5.45977 & -1.79743 \\
6. a) Extrinsic Prothrombin Activation; & Hsa-miR-1537 & 0.957082 & & \\
b) Intrinsic Prothrombin Activation & Hsa-miR-210 & 1592.884 & 0.333333 & 1.091521 \\
& Hsa-miR-99a & 4268.871 & 317.8046 & 2.397213 \\
& Hsa-miR-381 & 138.0215 & 10953.55 & -1.71181 \\
\hline
\end{tabular}

Table 3 Luminal B: frequency of pairwise pathways in the top 10 for all 50 bootstraps

\begin{tabular}{|c|c|}
\hline Pairwise pathway & Frequency \\
\hline 1) Wnt/catenin Signalling;Mitotic Roles of Polo-Like Kinase & $46 / 50$ \\
\hline $\begin{array}{l}\text { 2) Epithelial Adherens Junction Signalling; Mitotic Roles } \\
\text { of Polo-Like Kinase }\end{array}$ & $39 / 50$ \\
\hline $\begin{array}{l}\text { 3) Mitotic Roles of Polo-Like Kinase; Growth Hormone } \\
\text { Signalling }\end{array}$ & $26 / 50$ \\
\hline $\begin{array}{l}\text { 4) Wnt/catenin Signalling;Cell Cycle Control of } \\
\text { Chromosomal Replication }\end{array}$ & $20 / 50$ \\
\hline $\begin{array}{l}\text { 5) LPS/LL1 Mediated Inhibition of RXR Function; } \\
\text { Assembly of RNA Polymerase II Complex }\end{array}$ & $11 / 50$ \\
\hline $\begin{array}{l}\text { 6) Calcium Signalling;Cell Cycle Control of Chromosomal } \\
\text { Replication }\end{array}$ & $11 / 50$ \\
\hline 7) Mitotic Roles of Polo-Like Kinase;RhoA Signalling & $11 / 50$ \\
\hline $\begin{array}{l}\text { 8) Epithelial Adherens Junction Signalling; } \\
\text { Cell Cycle Control of Chromosomal Replication }\end{array}$ & $10 / 50$ \\
\hline $\begin{array}{l}\text { 9) Mitotic Roles of Polo Like Kinase; Factor Promoting } \\
\text { Cardiogenesis in Vertebrates }\end{array}$ & $9 / 50$ \\
\hline 10) Epithelial Adherens Junction Signalling; EIF2 Signalling & $9 / 50$ \\
\hline 11) Acute Phase Response Signalling; HIF1 Signalling & $9 / 50$ \\
\hline $\begin{array}{l}\text { 12) Cellular Effects of Sildenafil (Viagra); Cell Cycle Control } \\
\text { of Chromosomal Replication }\end{array}$ & $9 / 50$ \\
\hline 13) ILK Signalling;Mitotic Roles of Polo-Like Kinase & $9 / 50$ \\
\hline $\begin{array}{l}\text { 14) Glioblastoma Multiforme Signalling; Mitotic Roles of } \\
\text { Polo-Like Kinase }\end{array}$ & $8 / 50$ \\
\hline $\begin{array}{l}\text { 15) LPS/IL-1 Mediated Inhibition of RXR Function; } \\
\text { linolenate Biosynthesis II (Animals) }\end{array}$ & $7 / 50$ \\
\hline & \\
\hline 50$)$. & $1 / 50$ \\
\hline
\end{tabular}

Dots indicate the other pairs of pathways with minor frequency
Signalling; Mitotic Roles of Polo-Like Kinase) have excellent AUC in most bootstraps.

Figure 7 shows the inter-pathway coordination among the top 10 pairwise pathways in luminal $\mathrm{B}$. We found only 3 miRNAs significantly deregulating 1 pairwise pathway (Epithelial Adherens Junction Signalling; EIF2 Signalling) which are also shown. Among pathways, the role of Mitotic Roles of Polo-like Kinase, hub of a network linking RhoA Signalling, Epithelial Adherens Junction Signalling, Wnt/catenin Signalling, Factors Promoting Cardiogenesis in Vertebrates, and Growth Hormone Signalling appears dominant.

Table 4 lists, for the above mentioned pairwise pathway, its miRNA regulators, their expression levels in BC luminal $\mathrm{B}$ and in NS, and the statistical significance of the comparison (in terms of log Fold Change).

The results of the MI analysis for the identification of candidate genes target of miRNAs are shown in the Additional file 2.

\section{Basal vs. Normal}

After 50 bootstraps, we found 74 pairwise pathways enriched with 6011 differentially expressed genes, since many pathways were found in common among the top 10 pairs in many bootstraps.

The final top 10 pairwise pathways, selected according to their frequency in the top 10 in all bootstraps from the 74 pairwise pathways, are shown in Table 5.

Figure 8 shows a boxplot with the AUC values for the final 10 pairwise pathways in both the training and 


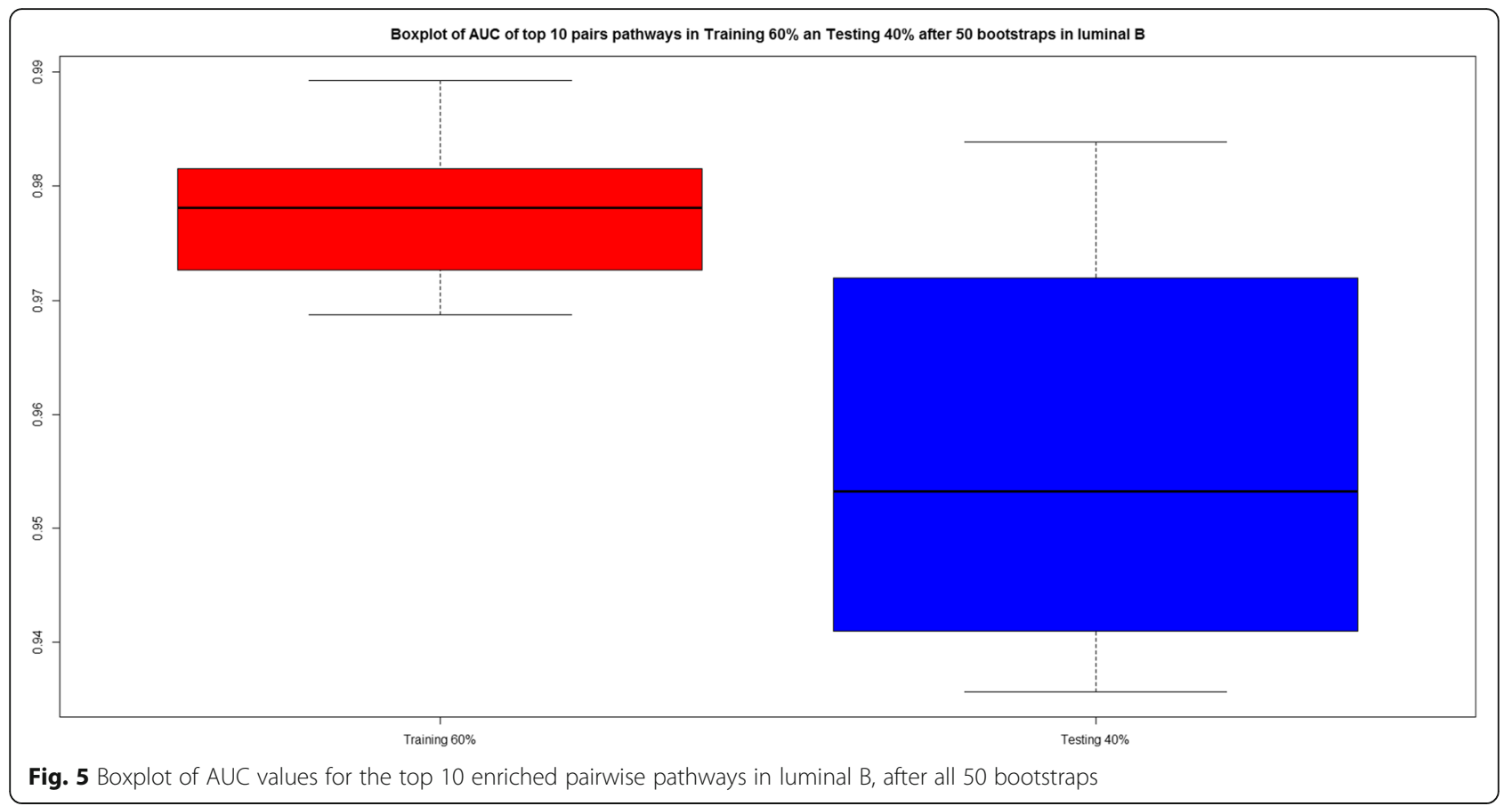

testing phase, confirming the good AUC (median >95\%) both for training and testing.

Figure 9 shows, for each bootstrap, the AUC of the top 10 pairs of pathways, confirming also for basal, that some pairwise pathways (e.g. Ethanol Degradation IV;
Role of BRCA1 in DNA Damage Response, and Putrescine Degradation III; Mismatch Repair in Eukaryotes) have excellent AUC in most bootstraps.

Figure 10 shows the inter-pathway coordination among the top 10 pairwise pathways in $\mathrm{BC}$ basal. We found only

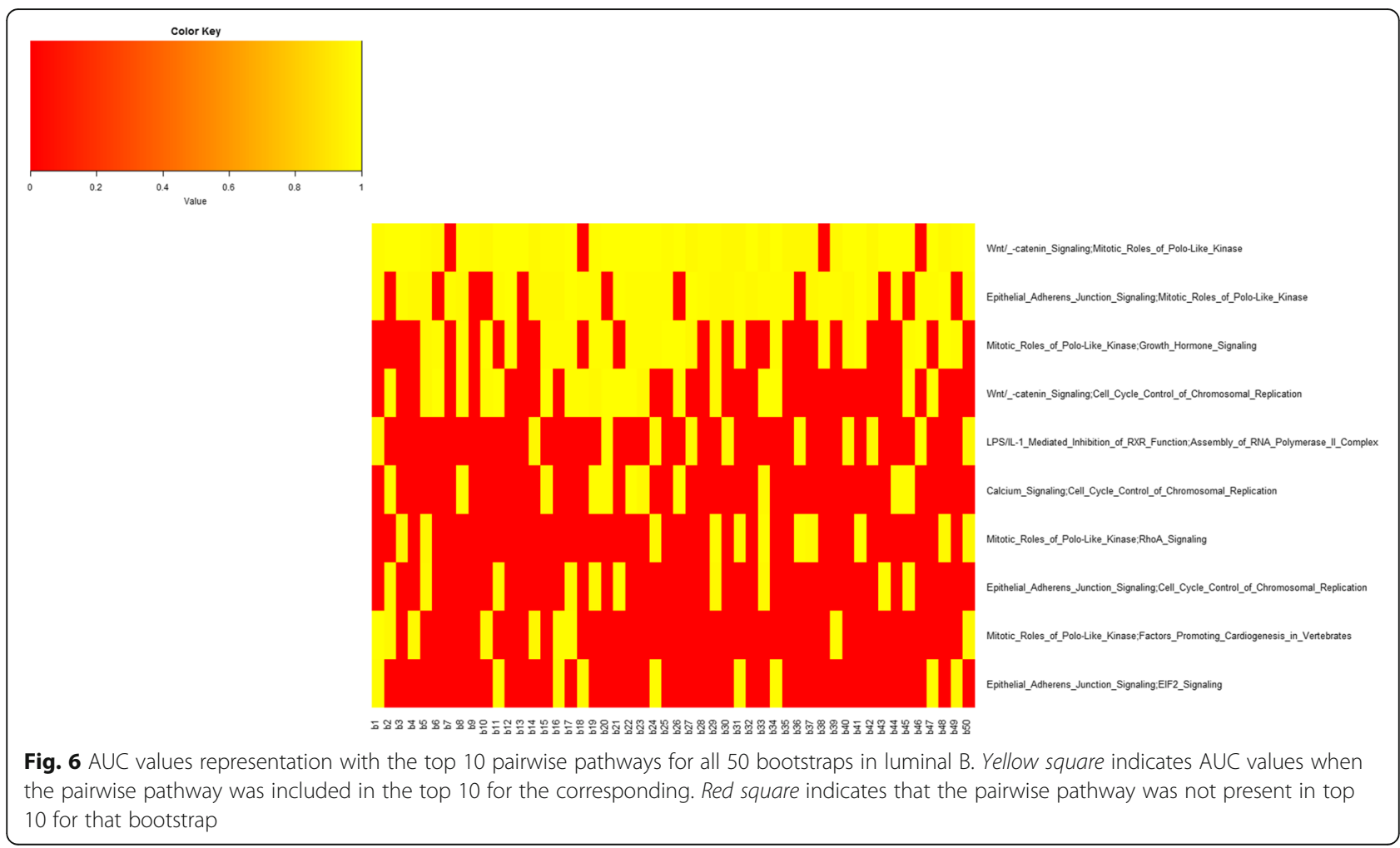




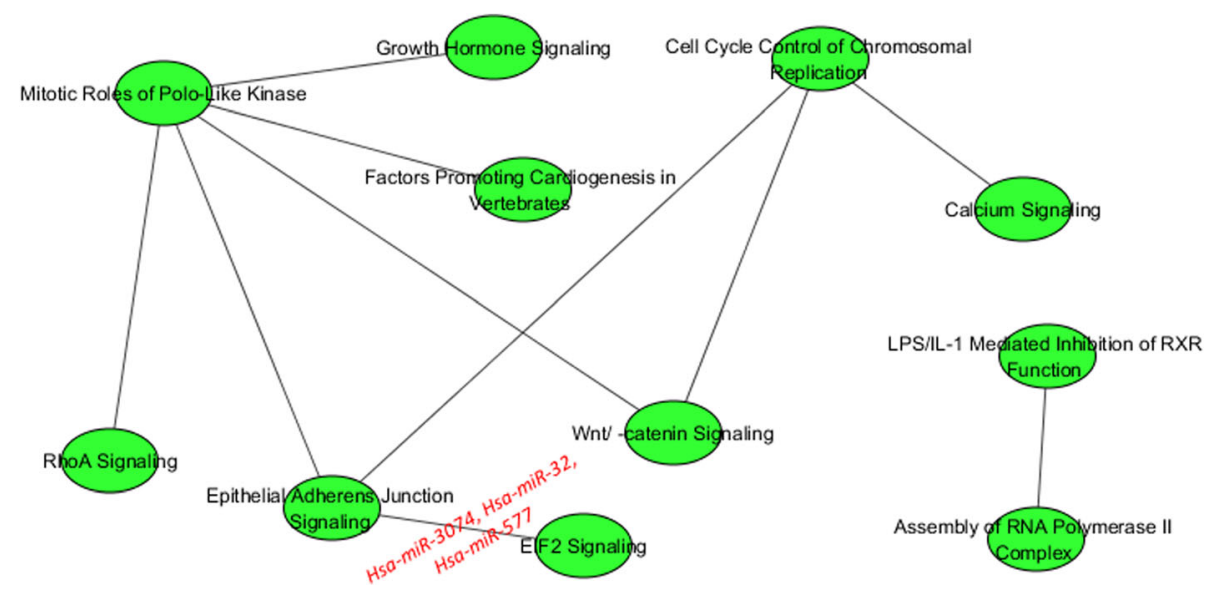

Fig. 7 Interaction of the top 10 pairwise pathways in luminal B and their miRNA-r in luminal B BC

2 miRNAs significantly deregulating 3 pairwise pathways: 1) Ethanol Degradation IV; Mismatch Repair in Eukaryotes, 2) Putrescine Degradation III; Role of BRCA1 in DNA Damage Response, 3) Tryptophan Degradation X (Mammalian, via Tryptamine); Role of BRCA1 in DNA Damage Response, which are also shown. Among pathways, the role of BRCA1 in DNA Damage Response, hub of a network linking Putrescine Degradation III, Ethanol Degradation IV, Ethanol Degradation II, Histamine Degradation, Oxidative Ethanol Degradation III, and Tryptophan Degradation X appears dominant.

Table 6 lists, for the 3 above mentioned pairwise pathways, miRNA regulators of pathways, their expression levels in BC basal and in NS, and the statistical significance of the comparison (in terms of log Fold Change).

The results of the MI analysis for the identification of candidate genes target of miRNAs are shown in the Additional file 3.

\section{HER2 vs. Normal}

After 50 bootstraps, we found 222 pairwise pathways enriched with 4464 differentially expressed genes.

The final top 10 pairwise pathways, selected according to their frequency in the top 10 in all bootstraps from the 222 pairwise pathways, are shown in Table 7 .

Figure 11 shows a boxplot with the AUC values for the final 10 pairwise pathways in both the training and testing phase, confirming good AUC (median >90\%), both for training and testing.

Figure 12 shows, for each boostrap, the AUC of the top 10 pairs of pathways, confirming that some pairwise pathways (e.g. Axonal Guidance Signalling;CXCR4 Signalling, Atherosclerosis Signalling; Acute Phase Response Signalling) have excellent AUC in most bootstraps.

Figure 13 shows the inter-pathway coordination among the top 10 pairwise pathways in BC HER2. We found 14 miRNAs significantly deregulating 7 pairwise pathways which are also shown 1) Acute Phase Response Signalling; HIF1 Signalling, 2) Atherosclerosis Signalling; Acute Phase Response Signalling, 3) Axonal Guidance Signalling; CXCR4 Signalling, 4) Axonal Guidance Signalling; P2Y Purigenic Receptor Signalling Pathway 5) HIF1 Signalling; Glioblastoma Multiforme Signalling 6) HIF1 Signalling; Growth Hormone Signalling, 7) Role of Macrophages, Fibroblasts and Endothelial Cells in Rheumatoid Arthritis; Growth Hormone Signalling. Among pathways, the role of Growth Hormone Signalling, hub of a network linking Axonal Guidance Signalling, HIF1 Signalling, Role of Macrophages, Fibroblasts and Endothelial Cells in Rheumatoid Arthritis appears dominant.

Table 8 lists, for each of the seven pairwise pathways, miRNA regulators of pathways, their expression levels in BC HER2 and in NS, and the statistical significance of the comparison (in terms of log Fold Change).

Table 4 For the top pairwise pathway in luminal B: miRNA regulators of the pathways, their expression levels in BC and in NS, and the statistical significance of the comparison (in terms of log Fold Change)

\begin{tabular}{lllll}
\hline Pairwise pathways & miRNA-r & miRNA-r Exp. in BC & miRNA-r Exp. in NS & Statistical significance (log Fold Change) \\
\hline 1. a) Epithelial Adherens Junction Signalling; & Hsa-miR-32 & 114.3883 & 50.54023 & 1.579455 \\
b) EIF2 Signalling & Hsa-miR-3074 & 77.45631 & 33.32184 & 1.368266 \\
& Hsa-miR-577 & 4.640777 & 15.78161 & -1.48828 \\
\hline
\end{tabular}


Table 5 Basal: frequency of pairwise pathways in the top 10 for all 50 bootstraps

\begin{tabular}{|c|c|}
\hline Pairwise pathway & Frequency \\
\hline $\begin{array}{l}\text { 1) Ethanol Degradation IV; Role of BRCA1 in DNA } \\
\text { Damage Response }\end{array}$ & $41 / 50$ \\
\hline 2) Putrescine Degradation III; Mismatch Repair in Eukaryotes & $40 / 50$ \\
\hline 3) Ethanol Degradation IV; Mismatch Repair in Eukaryotes & $36 / 50$ \\
\hline $\begin{array}{l}\text { 4) Role of BRCA1 in DNA Damage Response; } \\
\text { Oxidative Ethanol Degradation III }\end{array}$ & $35 / 50$ \\
\hline $\begin{array}{l}\text { 5) Ethanol Degradation } \| \text {; Role of BRCA1 in DNA } \\
\text { Damage Response }\end{array}$ & $31 / 50$ \\
\hline $\begin{array}{l}\text { 6) Role of BRCA1 in DNA Damage Response; } \\
\text { Histamine Degradation }\end{array}$ & $24 / 50$ \\
\hline $\begin{array}{l}\text { 7) Tryptophan Degradation X (Mammalian, via Tryptamine); } \\
\text { Role of BRCA1 in DNA Damage Response }\end{array}$ & $24 / 50$ \\
\hline $\begin{array}{l}\text { 8) Putrescine Degradation III;Role of BRCA1 in DNA } \\
\text { Damage Response }\end{array}$ & $23 / 50$ \\
\hline $\begin{array}{l}\text { 9) Role of BRCA1 in DNA Damage Response; Putrescine } \\
\text { Degradation III }\end{array}$ & $18 / 50$ \\
\hline $\begin{array}{l}\text { 10) Cell Cycle Control of Chromosomal Replication; } \\
\text { Cellular Effects of Sildenafil (Viagra) }\end{array}$ & $17 / 50$ \\
\hline $\begin{array}{l}\text { 11) Cell Cycle Control of Chromosomal Replication; } \\
\text { Colorectal Cancer Metastasis Signalling }\end{array}$ & $16 / 50$ \\
\hline $\begin{array}{l}\text { 12) Oxidative Ethanol Degradation III; Role of BRCA1 } \\
\text { in DNA Damage Response }\end{array}$ & $14 / 50$ \\
\hline $\begin{array}{l}\text { 13) Role of BRCA1 in DNA Damage Response; } \\
\text { Ethanol Degradation II }\end{array}$ & $13 / 50$ \\
\hline $\begin{array}{l}\text { 14) Cell Cycle Control of Chromosomal Replication; } \\
\text { eNOS Signalling }\end{array}$ & $12 / 50$ \\
\hline 15) Mismatch Repair in Eukaryotes; Fatty Acid -oxidation I & $12 / 50$ \\
\hline \multicolumn{2}{|l|}{$\ldots$} \\
\hline 50).... & $1 / 50$ \\
\hline
\end{tabular}

Dots indicate the other pairs of pathways with minor frequency

The results of the MI analysis for the identification of candidate genes target of miRNAs are shown in the Additional file 4.

\section{Discussion}

In a normal condition the biological pathways act in a coordinated way to collaborate in a biological process. Cancer can interfere in these coordinated processes, since alterations in multiple genes that participate in different pathways result in an uncontrolled growth of tumour cells, invasion and metastases.

In this work, by assessing the coordination among different pathways deregulated in $\mathrm{BC}$ subtypes, we observed key pairwise pathways for each $\mathrm{BC}$ subtype, which enabled the identification of a network of dependent pathways characteristic of the disease. Furthermore, we identified miRNAs that control this network with a potential role in BC. These miRNAs could be crucial modulators of upstream signalling events linked by specific subtype of BC.
miRNAs regulating pathways in luminal $\mathrm{A}$

In BC luminal A we identified 11 miRNAs (Hsa-miR-1-1, Hsa-miR-1250, Hsa-miR-1537, Hsa-miR-205, Hsa-miR210, Hsa-miR-3199-1, Hsa-miR-335, Hsa-miR-337, HsamiR-381, Hsa-miR-452, and Hsa-miR-99a) which could be key modulators of six pairs of pathways: 1) Intrinsic Prothrombin Activation, and Extrinsic Prothrombin Activation; 2) Acute Phase Response Signalling, and HIF1 Signalling 3) Axonal Guidance Signalling, and Acute Phase Response Signalling; 4) Ethanol Degradation IV, and Glioma Invasiveness Signalling; 5) Ethanol Degradation IV, and Estrogen Receptor Signalling; and 6) Glioma Invasiveness Signalling, and Oxidative Ethanol Degradation III.

\section{Intrinsic prothrombin activation and extrinsic prothrombin activation, regulated by Hsa-miR-99a, Hsa-miR-210, Hsa-miR-381, and Hsa-miR-1537}

Intrinsic and extrinsic prothrombin activation pathways perform an essential role in coagulation, an important process for the establishment of metastasis also in experimental models of cancer [70].

Hsa-miR-99a has been already associated with BC; in particular, its up regulation correlates with cells with stemness properties [71]. Moreover, Hsa-miR-99a has been identified in a screening of miRNA profiles able to discriminate ductal carcinoma in situ, invasive BC, metastatic $\mathrm{BC}$ and normal tissues. Hsa-miR-99a shows specific differential expression in the in situ subtype of $B C$ [72]. Among the other miRNAs regulating the two above mentioned pathways, Hsa-miR-381 is one of the possible circulating miRNAs able to discriminate between blood samples of patients with $\mathrm{BC}$ and NC [73]. Hsa-miR-210 was demonstrated to be a potential predictor of the outcome of different cancers, including BC [74]. Circulating Hsa-miR-210 levels were associated with trastuzumab sensitivity, tumour presence, and lymph node metastases, suggesting $H s a-m i R-210$ as a predictor and perhaps a monitor of the response to therapies including trastuzumab [75].

Limited data about Hsa-miR-1537 is available for this miRNA. Few publications, not related to $B C$, described this miRNA as altered in the serum and bile of cholangioma patients [76], where a speculation of a role for Hsa-miR-1537 in inflammation is proposed.

\section{Acute phase response signalling and HIF1 signalling, regulated by Hsa-miR-205}

The acute phase response is a rapid inflammatory response that provides protection against infections, including cancer [77]. Several studies found cross-talk between HIF-1 signalling and inflammatory pathways suggesting that the development of inflammation in response to hypoxia is clinically relevant [78]. 


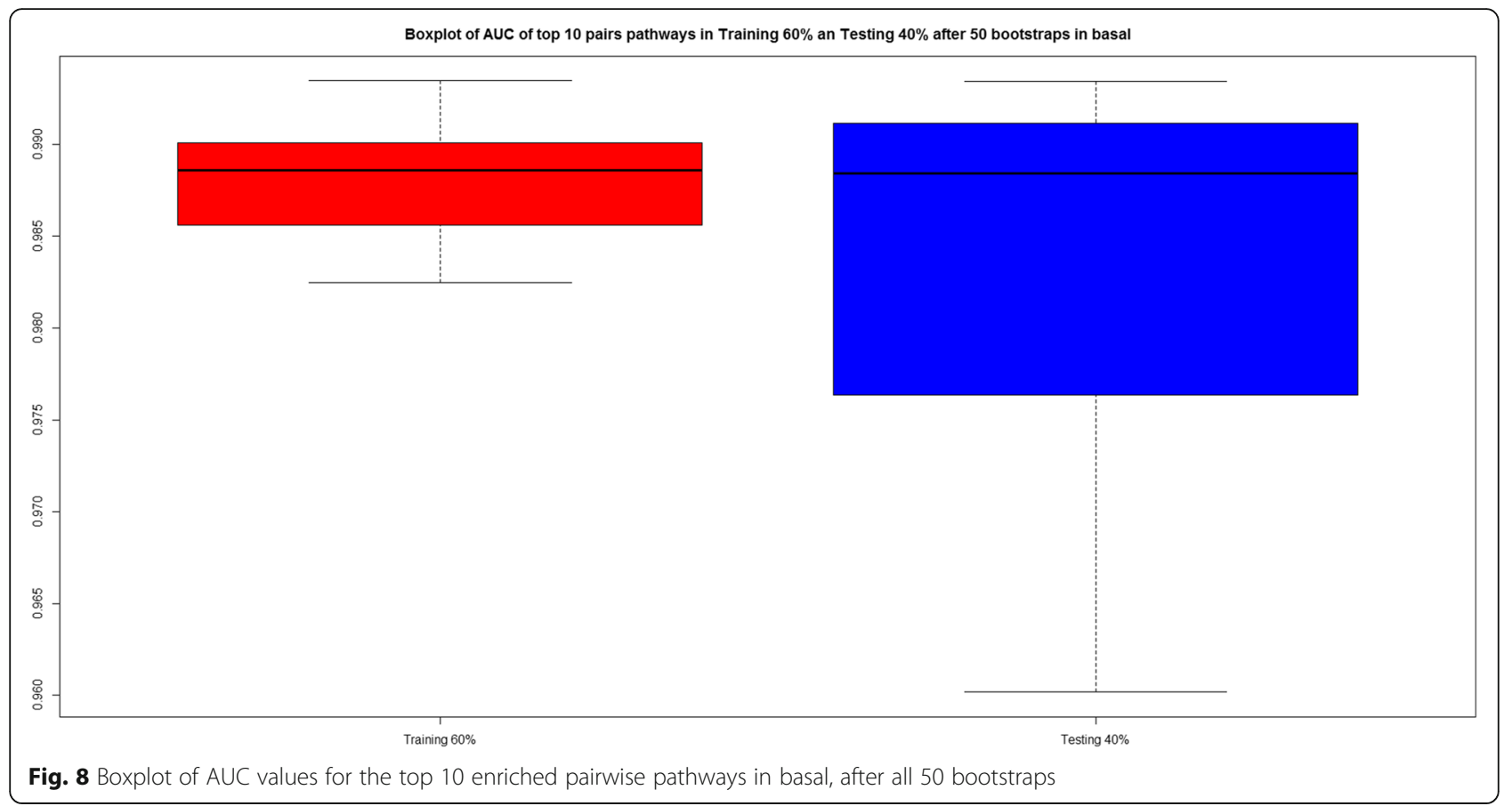

Hsa-miR-205 is an oncosuppressive miRNA lost in BC; it is directly transactivated by the oncosuppressor p53 [79]. Sempere et al. [80] showed that Hsa-miR-205 expression is restricted to the myoepithelial/basal cell compartment of normal mammary ducts and lobules, and is reduced or completely eliminated in matching tumour specimens. Hsa-miR-205 regulates a number of important oncogenic targets as ZEB1,VEGFA, and HER3. Moreover, it may modulate additional targets, such as HMGB3, showing a potential therapeutic benefit/role [81].

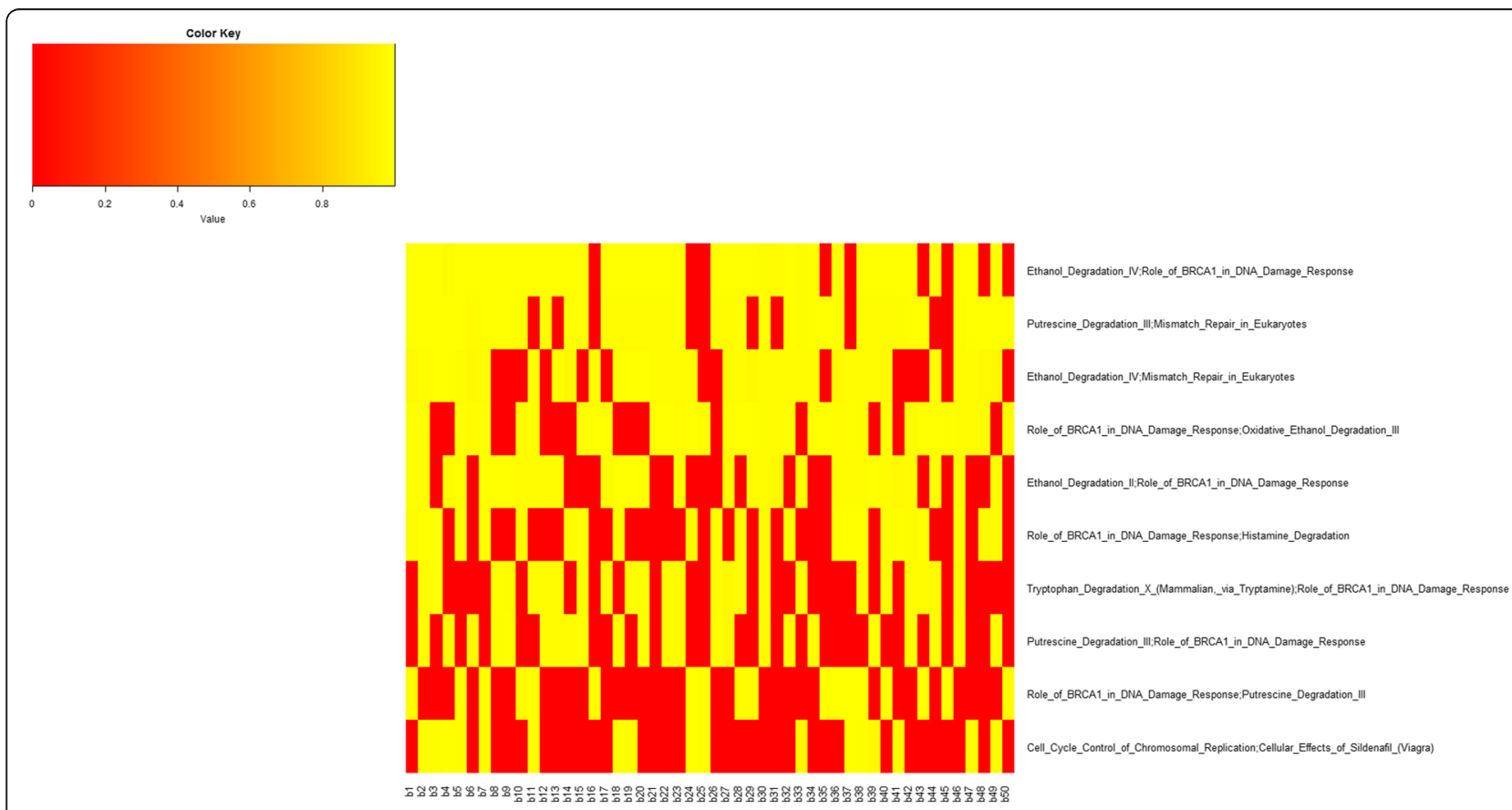

Fig. 9 AUC values representation with the top 10 pairwise pathways for all 50 bootstraps in basal. Yellow square indicates AUC values when the pairwise pathway was included in the top 10 for the corresponding bootstrap. Red square indicates that the pairwise pathway was not present in top 10 for that bootstrap 


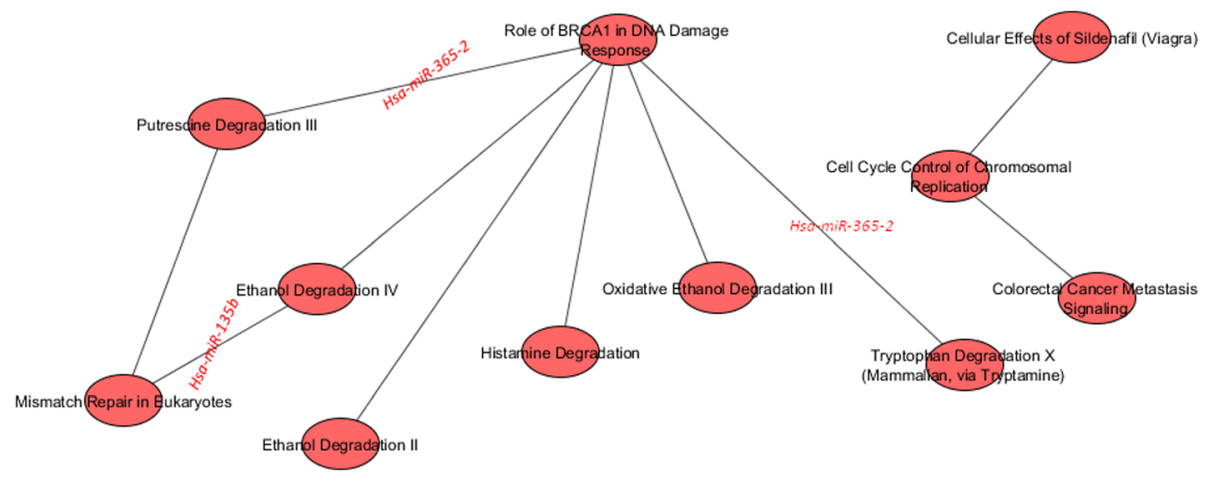

Fig. 10 Interaction of the top 10 pairwise pathways in BC basal and their miRNA-r in BC basal

Axonal guidance signalling and acute phase response signalling, regulated by Hsa-miR-205, Hsa-miR-99a, Hsa-miR-335, Hsa-miR-337, Hsa-miR-452, and Hsa-miR-1250 We found that two pathways, Axonal Guidance Signalling and Acute Phase Response Signalling, are regulated by a group of 6 miRNAs.

There are four families of secreted or membranebound factors with repulsive or attractive activities for growing axons and migrating neurons (i.e., netrin 1, semaphorine, ephrins, and Slit, all with their receptors), which have recently emerged as pivotal factors in tumour progression. Far from being confined to the developing brain, axonal guidance signalling seems to play an important role in tumour cell migration, tumour cell survival and tumour angiogenesis [82].

Hsa-miR-205 has already been proposed as a circulating biomarker of the response of the $\mathrm{BC}$ luminal A subtype to neoadjuvant chemotherapy [83].

Hsa-miR-335 is down regulated in cancer stem cells (CSC) targeting genes, such as Bmil and Suz12 component, Zeb1/2, and $K l f 4$, all belonging to a regulatory circuit that sustains the breast CSC state [84]. Hsa-miR335 could be used as prognostic marker [85] and could suppress neuroblastoma cell invasiveness by directly targeting multiple genes from the non-canonical TGF- $\beta$ signalling pathway [86].

Hsa-miR-337 plays a role in the reduction of gastric cancer cell invasion capacity and its loss has been associated with lymph node metastasis [87]. Furthermore, a study in prostate cancer revealed $\mathrm{Hsa}-\mathrm{miR}-337$ as a potential circulating biomarker able to identify risk groups [88].

Hsa-miR-452 has been found to be associated with adriamycin-resistance of $\mathrm{BC}$ cells, at least, partially, by targeting the insulin-like growth factor-1 receptor (IGF-1R) [89], and contributes to the docetaxel resistance of $\mathrm{BC}$ cells [90].

Hsa-miR-1250 has been described in the white matter tracts of the human brain. Although no publication is available regarding its role in $\mathrm{BC}, \mathrm{Hsa}-\mathrm{miR}-1250$ seems to perform a role in oligodendrocyte proliferation and differentiation [91].

\section{Ethanol degradation IV, and glioma invasiveness signalling regulated by Hsa-miR-3199-1}

Looking to the list of genes in Ethanol Degradation IV, we found that a lot of these genes belong to the family of $A L D H$ genes, and, although as they perform a role in ethanol detoxification, they are also considered biomarkers of CSCs [92].

$\mathrm{ER}+$ cells are able to generate cell progeny of luminal lineage both in vitro and in vivo. Loss of $A L D H$ isoform, $A L D H 1 A 1$, plays a role in this process by weakening cellular differentiation [93]. Several studies demonstrated that $A L D H 1 A 1$ correlates with $\mathrm{ER}$ status in $\mathrm{BC}$, and that

Table 6 For each top 3 pairwise pathway in BC basal: miRNA regulators of pathways, their expression levels in BC and in NS, and the statistical significance of the comparison (in terms of log Fold Change)

\begin{tabular}{llccc}
\hline Pairwise pathways & miRNA-r & miRNA-r Exp. in BC & miRNA-r Exp. in NS & Statistical significance (log Fold Change) \\
\hline $\begin{array}{l}\text { 1. a) Ethanol Degradation IV; } \\
\text { b) Mismatch Repair in Eukaryotes }\end{array}$ & Hsa-miR-135b & 342.0541 & 13.01149 & 4.96603 \\
$\begin{array}{l}\text { 2. a) Putrescine Degradation III; } \\
\text { b) Role of BRCA1 in DNA Damage Response }\end{array}$ & Hsa-miR-365-2 & 153.5541 & 506.0575 & -1.39949 \\
$\begin{array}{l}\text { 3. a) Tryptophan Degradation X (Mammalian, } \\
\text { via Tryptamine); }\end{array}$ Hsa-miR-365-2 & 153.5541 & 506.0575 & -1.39949 \\
b) Role of BRCA1 in DNA Damage Response & & & & \\
\hline
\end{tabular}


Table 7 HER2: frequency of pairwise pathways in the top 10 for all 50 bootstraps

\begin{tabular}{|c|c|}
\hline Pairwise pathway & Frequency \\
\hline 1) Axonal Guidance Signalling; CXCR4 Signalling & $18 / 50$ \\
\hline $\begin{array}{l}\text { 2) Atherosclerosis Signalling; Acute Phase Response } \\
\text { Signalling }\end{array}$ & $16 / 50$ \\
\hline $\begin{array}{l}\text { 3) Role of Macrophages, Fibroblasts and Endothelial } \\
\text { Cells in Rheumatoid Arthritis; Growth Hormone Signalling }\end{array}$ & $12 / 50$ \\
\hline 4) HIF1 Signalling; Glioblastoma Multiforme Signalling & $11 / 50$ \\
\hline $\begin{array}{l}\text { 5) Putrescine Degradation III; NAD biosynthesis II } \\
\text { (from tryptophan) }\end{array}$ & $11 / 50$ \\
\hline 6) HIF1 Signalling; Growth Hormone Signalling & $11 / 50$ \\
\hline $\begin{array}{l}\text { 7) Axonal Guidance Signalling; P2Y Purigenic Receptor } \\
\text { Signalling Pathway }\end{array}$ & $10 / 50$ \\
\hline 8) Acute Phase Response Signalling; HIF1 Signalling & $8 / 50$ \\
\hline 9) Axonal Guidance Signalling; Growth Hormone Signalling & $7 / 50$ \\
\hline 10) Cellular Effects of Sildenafil (Viagra); tRNA Charging & $7 / 50$ \\
\hline $\begin{array}{l}\text { 11) Hepatic Fibrosis/Hepatic Stellate Cell Activation; } \\
\text { Coagulation System }\end{array}$ & $6 / 50$ \\
\hline $\begin{array}{l}\text { 12) Acute Phase Response Signalling; Role of Macrophages, } \\
\text { Fibroblasts and Endothelial Cells in Rheumatoid Arthritis }\end{array}$ & $6 / 50$ \\
\hline 13) Retinoate Biosynthesis l; Estrogen Receptor Signalling & $6 / 50$ \\
\hline $\begin{array}{l}\text { 14) Factors Promoting Cardiogenesis in Vertebrates; } \\
\text { tRNA Charging }\end{array}$ & $6 / 50$ \\
\hline $\begin{array}{l}\text { 15) Role of Macrophages, Fibroblasts and Endothelial } \\
\text { Cells in Rheumatoid Arthritis; Role of BRCA1 in } \\
\text { DNA Damage Response }\end{array}$ & $6 / 50$ \\
\hline 50).... & $1 / 50$ \\
\hline
\end{tabular}

Dots indicate the other pairs of pathways with minor frequency
$A L D H 1 A 1$ is an independent predictor of poor clinical outcome $[94,95]$.

Looking at the list of genes involved in glioma invasiveness signalling, we found several genes such as ITGB5, belonging to the integrins family, the integrin signalling members (Rhoh, Rhou and VTN) or some members of phosphatidylinositol 3-kinase (PI3K) signalling $(P I K 3 C 2 B, P I K 3 C B)$. Integrins comprise a large family of cell surface receptors and control cell attachment to the extracellular matrix $(E C M)$, growth, differentiation, apoptosis, cell motility, migration and survival. A role for integrins in BC development has been already described [96]. Rhoh and Rhou proteins have a critical role in the tumour progression and invasion, being important for the transduction of the signal from integrins to the neighbourhood cell during cell-cell communication $[97,98]$. The PI3K signalling pathway in $\mathrm{BC}$ is associated with the poor outcome luminal B subtype, as its activation leads to the development of endocrine therapy resistance [99].

As regards $H s a-m i R-3199-1$, no publication is available on $\mathrm{BC}$ or on other cancer types.

\section{Ethanol degradation IV and estrogen receptor signalling, regulated by Hsa-miR-1-1}

We have already previously discussed the role of genes comprised in the list of Ethanol Degradation IV pathway.

As regards the pathway of Estrogen Receptor Signalling, ERs are critical regulators of breast epithelial cell proliferation, differentiation, and apoptosis. Nowadays

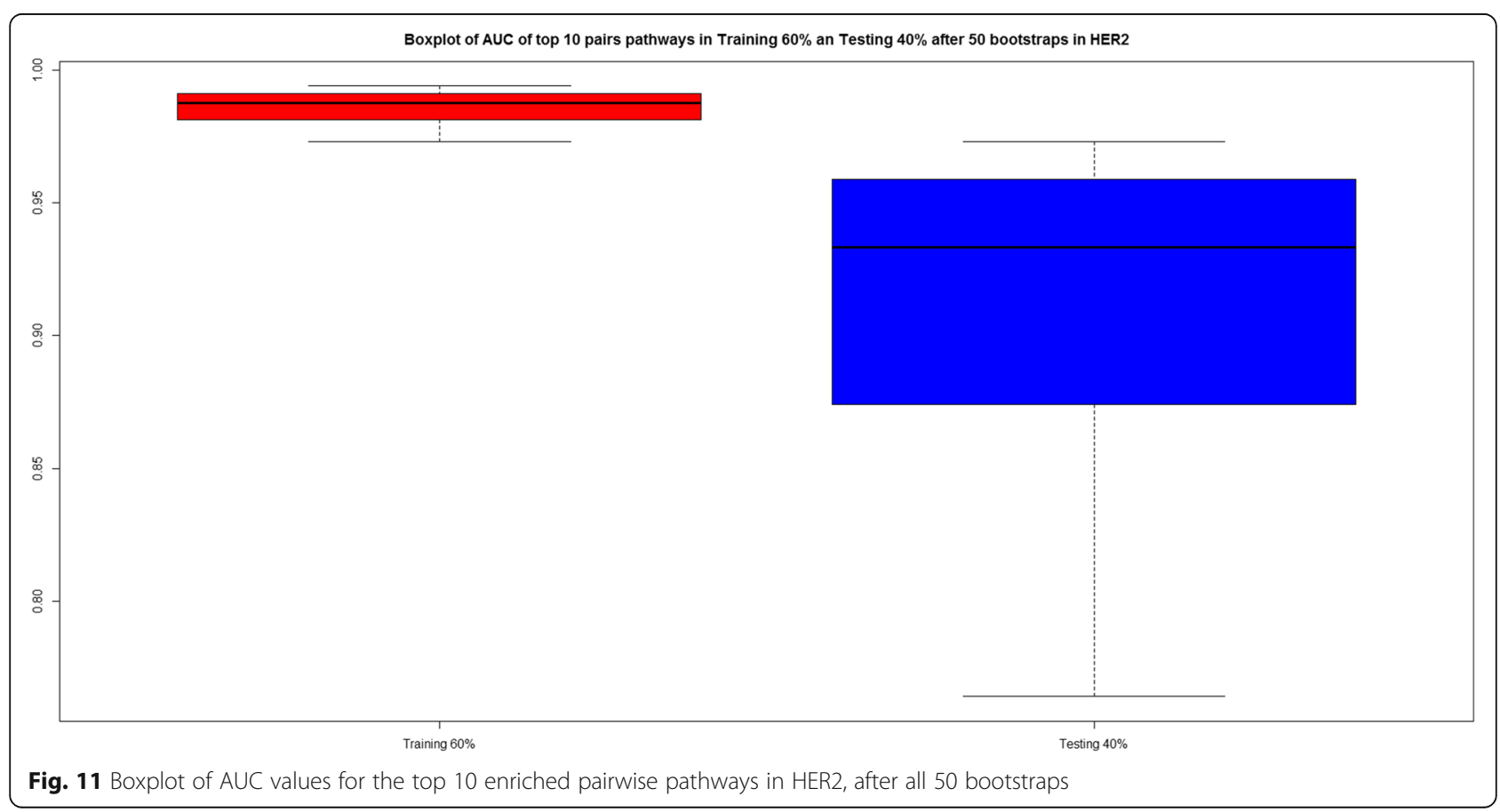




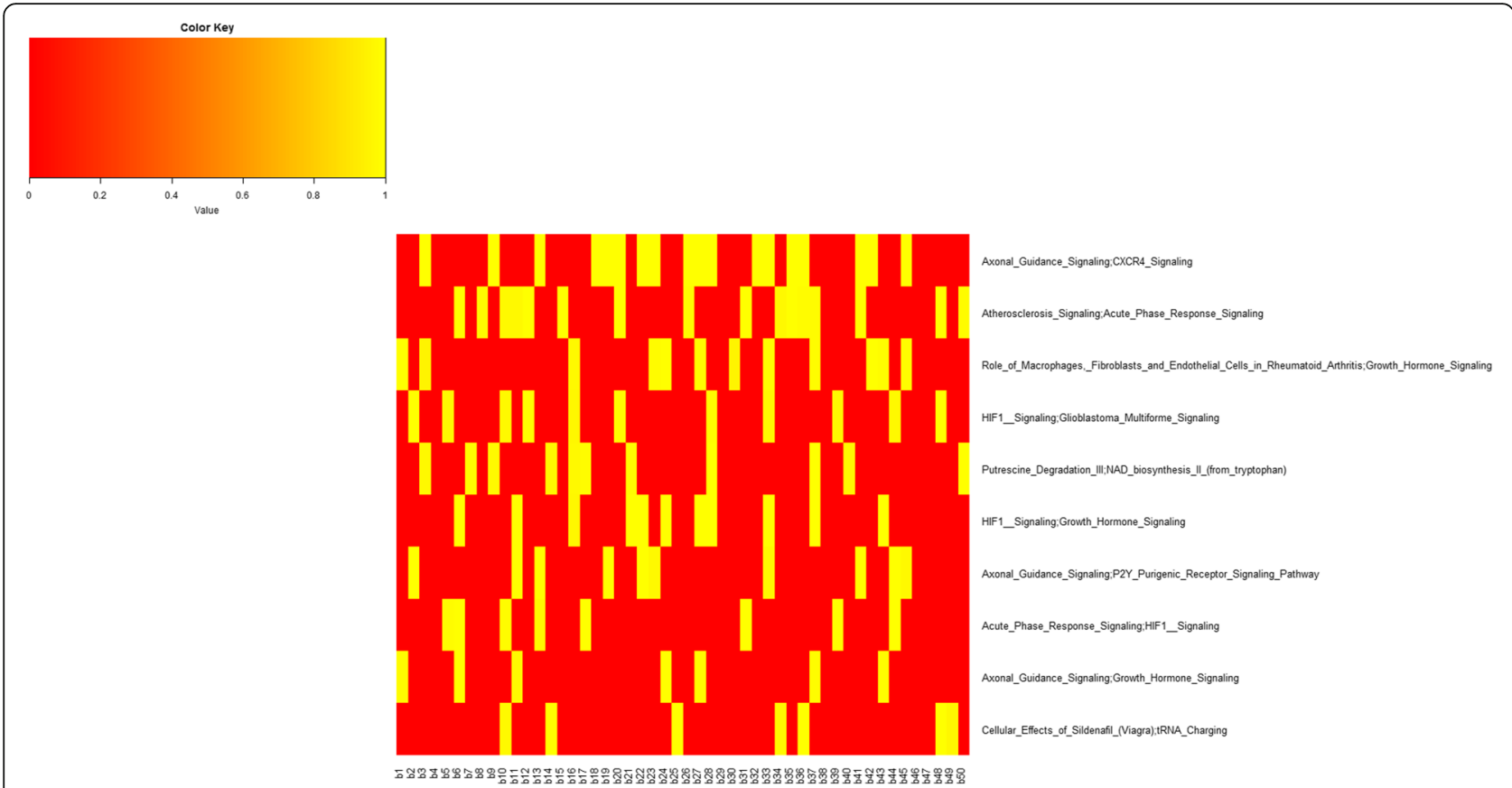

Fig. 12 AUC values representation with the best top 10 pairwise pathways for all 50 bootstraps in HER2. Yellow square indicates AUC values when the pairwise pathway was included in the top 10 for the corresponding bootstrap. Red square indicates that the pairwise pathway was not present in top 10 for that bootstrap

the role of ER pathway in BC malignancy development is quite clear. This is the reason why several therapeutic approaches have been directed against ER+ BC [100].

Hsa-miR-1-1 has been demonstrated to be a tumour suppressor gene that represses cancer cell proliferation and metastasis and promotes apoptosis by ectopic expression [101]. Hsa-miR-1-1 regulates downstream functions of oncogenic signalling pathways such as Met, HDAC4, PIM-1, Wnt, Cyclin D, FOXP1, Slug, and TAGLN2 [101]. Down regulation of Hsa-miR-1-1 was found to be associated with colorectal cancer progression [102].

\section{Glioma Invasiveness Signalling, and Oxidative Ethanol Degradation III regulated by Hsa-miR-3199-1}

As regards the pathway of Glioma Invasiveness Signalling, we have already discussed the role of its genes previously.

Looking at the list of genes involved in Oxidative Ethanol Degradation III, regulated by Hsa-miR-31991, we found some isoforms of the Phosphatidylinositol

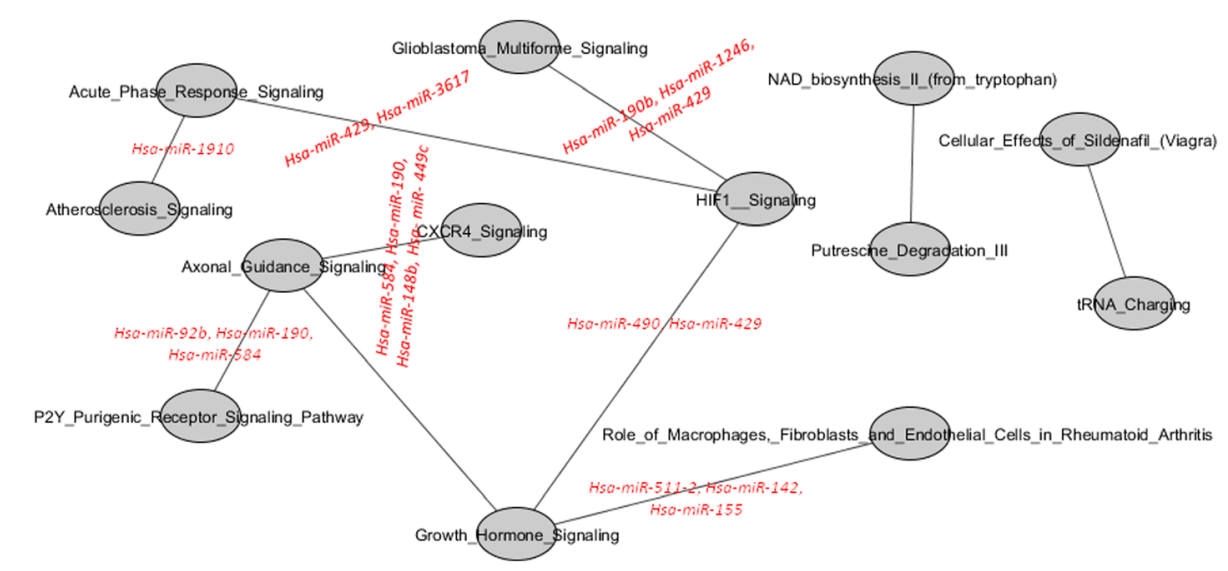

Fig. 13 Interaction of the top 10 pairwise pathways in HER2 BC and their miRNA-r in BC HER2 
Table 8 For each top 7 pairwise pathway in BC HER2: miRNA regulators of pathways, their expression levels in BC and in NS, and the statistical significance of the comparison (in terms of log Fold Change)

\begin{tabular}{|c|c|c|c|c|}
\hline Pairwise pathways & miRNA-r & miRNA-r Exp. in BC & miRNA-r Exp. in NS & $\log \mathrm{FC}$ \\
\hline $\begin{array}{l}\text { 1. a) Acute Phase Response Signalling; } \\
\text { b) HIF1 Signalling }\end{array}$ & $\begin{array}{l}\text { Hsa-miR-429 } \\
\text { Hsa-miR-3617 }\end{array}$ & $\begin{array}{l}434.2326 \\
0.209302\end{array}$ & $\begin{array}{l}71.18391 \\
0.045977\end{array}$ & $\begin{array}{l}2.604998 \\
1.078421\end{array}$ \\
\hline $\begin{array}{l}\text { 2. a) Atherosclerosis Signalling; } \\
\text { b) Acute Phase Response Signalling }\end{array}$ & Hsa-miR-1910 & 1.581395 & 0.425287 & 1.501305 \\
\hline $\begin{array}{l}\text { 3. a) Axonal Guidance Signalling; } \\
\text { b) CXCR4 Signalling }\end{array}$ & $\begin{array}{l}\text { Hsa-miR-584 } \\
\text { Hsa-miR-190 } \\
\text { Hsa-miR-148b } \\
\text { Hsa-miR-449c }\end{array}$ & $\begin{array}{l}152.5116 \\
11.60465 \\
719.4651 \\
5.651163\end{array}$ & $\begin{array}{l}482.4253 \\
31.05747 \\
315.1839 \\
0.068966\end{array}$ & $\begin{array}{l}-1.30985 \\
-1.02572 \\
1.550205 \\
5.430282\end{array}$ \\
\hline $\begin{array}{l}\text { 4. a) Axonal Guidance Signalling; } \\
\text { b) P2Y Purigenic Receptor Signalling Pathway }\end{array}$ & $\begin{array}{l}\text { Hsa-miR-92b } \\
\text { Hsa-miR-190 } \\
\text { Hsa-miR-584 }\end{array}$ & $\begin{array}{l}531.8605 \\
11.60465 \\
152.5116\end{array}$ & $\begin{array}{l}171.1494 \\
31.05747 \\
482.4253\end{array}$ & $\begin{array}{l}1.840728 \\
-1.02572 \\
-1.30985\end{array}$ \\
\hline $\begin{array}{l}\text { 5. a) HIF1 Signalling; } \\
\text { b) Glioblastoma Multiforme Signalling }\end{array}$ & $\begin{array}{l}\text { Hsa-miR-190b } \\
\text { Hsa-miR-1246 } \\
\text { Hsa-miR-429 }\end{array}$ & $\begin{array}{l}31.90698 \\
0.255814 \\
434.2326\end{array}$ & $\begin{array}{l}6.137931 \\
0.034483 \\
71.18391\end{array}$ & $\begin{array}{l}2.680854 \\
1.277809 \\
2.604998\end{array}$ \\
\hline $\begin{array}{l}\text { 6. a) HIF1 Signalling; } \\
\text { b) Growth Hormone Signalling }\end{array}$ & $\begin{array}{l}\text { Hsa-miR-490 } \\
\text { Hsa-miR-429 }\end{array}$ & $\begin{array}{l}5.395349 \\
434.2326\end{array}$ & $\begin{array}{l}0.298851 \\
71.18391\end{array}$ & $\begin{array}{l}4.276816 \\
2.604998\end{array}$ \\
\hline $\begin{array}{l}\text { 7. a) Role of Macrophages. Fibroblasts and Endothelial Cells in } \\
\text { Rheumatoid Arthritis; } \\
\text { b) Growth Hormone Signalling }\end{array}$ & $\begin{array}{l}\text { Hsa-miR-511-2 } \\
\text { Hsa-miR-142 } \\
\text { Hsa-miR-155 }\end{array}$ & $\begin{array}{l}17.69767 \\
11699.28 \\
1931.163\end{array}$ & $\begin{array}{l}56.51724 \\
3246.46 \\
616.9425\end{array}$ & $\begin{array}{l}-1.49388 \\
2.248187 \\
1.707846\end{array}$ \\
\hline
\end{tabular}

3-kinase (PI3K) protein. PI3K includes two subunits, $p 85 \alpha$ and $p 110 \alpha$, that are mediators of the prosurvival PI3K/Akt pathway signalling. Some isoforms of $P I 3 K$ as well as $p 85$ subunit have been already described in HER2-positive BC patients, responding to trastuzumab treatment [103]. Among the other genes, particularly interesting if the finding of ITGB5, an integrin belonging to a family of six genes (ITGA3, ITGA6, ITGAv, ITGB3, ITGB4 and ITGB5), which control cell attachment to the extracellular matrix and play an important role in mediating cell proliferation, migration and survival [104]. A strong association between integrin expression, mutation or polymorphism and $\mathrm{BC}$ onset has been already described [104].

The two described pathways seem to be controlled by a common miR, Hsa-miR-3199-1. No publication is currently available about the function of this miRNA in any biological processes.

\section{miRNAs regulating pathway in luminal $B$}

In BC luminal B, we identified 3 miRNAs (Hsa-miR-32, Hsa-miR-3074, and Hsa-miR-577), which could be key modulators of the pair of pathways Epithelial Adherens Junction Signalling - EIF2 Signalling.

\section{Epithelial adherens junction signalling and EIF2 signalling regulated by Hsa-miR-32, Hsa-miR-3074, and Hsa-miR-577}

Adherens junctions are specialist structures for cell-cell adhesion machinery. The adhesive process is directly related to the differentiation and normal development of the tissue [105]. The development of cancer represents a modification of normal tissue homeostasis and a change in cell-cell interaction. In addition, cancer metastasis spreads through the circulatory system due to cell adhesion [105].

EIF2 Signalling is an essential factor for translation initiation and protein synthesis. No study showed a correlation between these pathways.

Hsa-miR-32 is located in genomic regions, which might be involved in malignancies via deletion, amplification, or epigenetic modification mechanisms [106]. It regulates phosphatase and tensin homologue (PTEN) expression, and promotes proliferation, migration and invasion in colorectal cancer [107].

Hsa-miR-3074 has been associated with papillary renal cell carcinoma [108], but no publication is available about its role in $\mathrm{BC}$.

Hsa-miR-577 is mainly involved in proliferation control in glioblastoma [109], hepatocellular carcinoma [110] and in esophageal squamous cell carcinoma [111]. It is possible to hypothesise a role for Hsa-miR-577 also in BC proliferation control.

\section{miRNAs regulating pathway in basal}

In BC basal, we identified 2 miRNAs (Hsa-miR-135b, and Hsa-miR-365-2) that may play an important role in the regulation of three pairs of pathways: 1) Ethanol Degradation IV, and Mismatch Repair in Eukaryotes; 2) Putrescine Degradation III, and Role of BRCA1 in DNA Damage Response, and 3) Tryptophan Degradation X 
(Mammalian, via Tryptamine), and Role of BRCA1 in DNA Damage Response.

\section{Ethanol degradation IV and mismatch repair in eukaryotes, regulated by Hsa-miR-135b}

Mismatch Repair plays a key role in maintaining genomic stability. Cells possess multiple mechanisms to repair DNA damage and thus prevent mutations [112]. No study revealed a direct interaction between Ethanol Degradation IV, and Mismatch Repair in BC.

Hsa-miR-135b levels are elevated in a variety of cancers including BC [113]. Lowery et al. [113] identified a 15-miRNA predictive signature related to the expression of ER comprising also this miRNA (Hsa-miR-135b, HsamiR-190, Hsa-miR-217, Hsa-miR-218, Hsa-miR-299, and $H s a-m i R-342)$. Up regulation of $H s a-m i R-135 b$ is more robust in highly invasive than less invasive lines. In colorectal cancer, Hsa-miR-135b promotes cancer progression by acting as a downstream effector of oncogenic pathways [114].

\section{Putrescine degradation III, and role of BRCA1 in DNA damage response regulated by Hsa-miR-365-2}

Putrescine is a known metabolite that plays an important role in cancer and CSCs [115]. Putrescine belongs to the class of polyamine, involved in numerous processes in normal and cancer cells, such as proliferation, apoptosis, cell-cell interactions, and angiogenesis [116]. An association between the basal subtype and BRCA1 gene has been well described, and it may suggest that both inherent DNA damage-sensing processes and DNA repair mechanisms are crucial in the development of basal-like tumours [22, 23].

Hsa-miR-365-2 negatively regulates BCL2 protein levels, and its overexpression combined with the deregulation of other 2 miRNAs have an apoptotic effect thus suggesting a therapeutic potential [117]. In pancreatic cancer $\mathrm{Hsa}$ miR-365 was found to induce gemcitabine resistance by targeting the adaptor protein $\mathrm{SHC1}$ and pro-apoptotic regulator BAX [118].

\section{Tryptophan degradation $X$ (Mammalian, via Tryptamine), and role of BRCA1 in DNA damage response regulated by Hsa-miR-365-2}

Altered tryptophan metabolism is linked to cancer development and progression [119, 120]. In particular, indoleamine 2,3-dioxygenase 1 (IDO1), an enzyme involved in tryptophan degradation, has been documented to have therapeutic potential, alone or in combination with chemotherapy or immunotherapy [121]. Several studies confirmed its immunosuppressive role and the inhibition of the IDO1 pathway therefore represents a promising therapeutic approach. Clinical trials evaluating the first IDO1 inhibitors have already started
[122, 123]. The role of Hsa-miR-365 in cancer has been already reported above.

\section{miRNAs regulating pathway in HER2}

In HER2 BC, we identified 14 miRNAs (Hsa-miR-1246, Hsa-miR-142, Hsa-miR-148b, Hsa-miR-155, Hsa-miR-190, Hsa-miR-190b, Hsa-miR-1910, Hsa-miR-3617, Hsa-miR429, Hsa-miR-449c, Hsa-miR-490, Hsa-miR-511-2, HsamiR-584, Hsa-miR-92b) that may have an important role in the regulation of seven pairs of pathways: 1) Axonal Guidance Signalling; CXCR4 Signalling; 2) Axonal Guidance Signalling; P2Y Purigenic Receptor Signalling, 3) Role of Macrophages, Fibroblasts and Endothelial Cells in Rheumatoid Arthritis; Growth Hormone Signalling, 4) HIF1 Signalling; Growth Hormone Signalling, 5) HIF1 Signalling; Glioblastoma Multiforme Signalling, 6) Acute Phase Response Signalling; HIF1 Signalling, and 7) Atherosclerosis Signalling; Acute Phase Response Signalling.

Axonal guidance signalling and CXCR4 signalling, regulated by Hsa-miR-148b, Hsa-miR-190, Hsa-miR-449c, Hsa-miR-584 The role of Axonal Guidance Signalling in cancer has already been mentioned above. CXCR4 Signalling shows a down regulation in metastasised BC cells [124]. CXCR4, the receptor for stromal-derived factor-1, is already reported as involved in breast carcinogenesis and invasion. Recent studies showed that the inhibition of CXCR4 expression resulted in an anti-invasive effect revealing the potential for the treatment of $\mathrm{BC}$ [125].

$C X C R 4$, the receptor of $S D F-1$, plays a crucial role in modulating axonal responsiveness through a cyclic nucleotide-dependent signalling pathway [126].

Four miRNAs could be important regulator of this interaction.

Hsa-miR-148b was found to be a major coordinator of malignancy influencing invasion, survival to anoikis, extravasation, lung metastasis formation, and chemotherapy response [127]. Circulating Hsa-miR-148b was validated and found elevated in the plasma of $\mathrm{BC}$ patients compared to healthy women $[128,129]$. Cimino et al. [127] showed that Hsa-miR-148b expression enhances chemotherapy-induced apoptosis.

Hsa-miR-190 was associated with lymph node metastasis and its increased expression inhibited cell migration and invasiveness. The target of Hsa-miR-190 was proteaseactivated-receptor 1 (PAR-1), which is a metastasis promoting protein in several cancers [130].

$H s a-m i R-449 c$ showed a decreased expression in human gastric tumours and induces senescence and apoptosis by activating the p53 pathway [131]. No information is reported about $H s a-m i R-449 \mathrm{c}$ and $\mathrm{BC}$.

Hsa-miR-584 was found to be down-regulating TGF- $\beta$ in BC cells. PHACTR1, an actin-binding protein, is also 
regulated by $H s a-m i R-584$. Overexpression of $H s a-m i R-$ 584 and knockdown of PHACTR1 resulted in a drastic rearrangement of the actin cytoskeleton and in a loss of TGF- $\beta$-induced cell migration [132].

\section{Axonal guidance signalling and $P 2 Y$ purigenic receptor signalling pathway, regulated by Hsa-miR-190, Hsa-miR- 584, and Hsa-miR-92b}

The role of Axonal Guidance Signalling in cancer has already been mentioned above. A recent study showed that P2Y Purigenic Receptor Signalling Pathway is included in a potential pathway signature for testing Gemcitabine (Gem)-based chemotherapies sensitivity of gallbladder cancer patients [133].

P2Y receptors (e.g., P2Y1, P2Y2) have strong direct effects on the tumour by modulating cell growth. In vivo data support in vitro evidence that lowering the intratumour adenosine concentration and targeting the P2X7 receptor have a strong antitumour effect [134]. No study showed a direct interaction between Axonal Guidance Signalling and P2Y Purigenic Receptor Signalling.

Hsa-miR-190 has already been discussed above. As regards $H s a-m i R-584$, the involvement of this miRNA in the pathway controlled by TGF- $\beta$ [132] has been already described. In particular, TGF- $\beta$ is able to decrease the expression of Hsa-miR-584. This in turn leads to the increase of protein phosphatase and actin regulator 1 (PHACTR1), a protein required for TGF- $\beta$ induced cell migration of breast cancer cells [132]. The drastic reorganization of the actin cytoskeleton is important in axonal guidance signalling, playing a role in tumour cell migration, tumour cell survival and tumour angiogenesis.

Hsa-miR-92b, regulating these pairwise pathways, was found over-expressed in brain primary tumours, suggesting a functional link between neuronal stem cells and brain tumourigenesis [135]. The involvement of this miRNA in radiation resistance was also found [136].

\section{Role of macrophages, fibroblasts and endothelial cells in rheumatoid arthritis and growth hormone signalling, regulated by Hsa-miR-142, Hsa-miR-155, Hsa-miR-511-2} Tumours comprise proliferating tumour cells and stromal cells, including endothelial cells, inflammatory cells, and fibroblasts [137].

Macrophages play a crucial role in the innate and adaptive response to pathogens. Recently, it was also found that tumour-associated macrophages interact with CSCs thus leading to tumourigenesis, metastasis, and drug resistance [138]. As regards Hsa-miR-511-2, several publications demonstrated that this miRNA plays an important role in modulating tumour-associated macrophages. The upregulation of Hsa-miR-511 affects the pro-tumoural gene signature of tumour-associated macrophages, which are endowed with tissue-remodelling, proangiogenic, and protumoural activity $[139,140]$.

Hormones play an important role for normal development and possibly also for tumour formation in the mammary gland. Human growth hormone could also stimulate the tumour initiating capacity and metastasis of estrogen receptor-negative BC [141]. Hsa-miR-142 plays a role as potent inhibitor of human growth hormone signalling in normal and cancer cells thus suggesting the development of miRNA inhibitors as therapeutic agents in growth hormone-related disease, including cancer [142].

Hsa-miR-155, described as oncomiR, is implicated in EMT, cell migration, and invasion control. Roth et al. [143] found Hsa-miR-155 in the serum of patients with $\mathrm{BC}$ and not in healthy controls; this miRNA has been used to monitor the effect of taxane treatment on BC. Sun et al. observed the decreased expression of Hsa-miR-155 in serum after chemotherapy, which reached levels comparable to those of healthy subjects [144].

\section{HIF1 signalling and growth hormone signalling, regulated by Hsa-miR-490, Hsa-miR-429}

Resistance to hormonal therapy is still unknown, but hypoxia could play an important role, for instance, in down-regulating ER-alpha expression as well as ER-alpha function in BC cells [145]. Furthermore, hypoxia and estrogen are interchangeable as both similarly modulate epithelial-endothelial cell interaction [146].

Previous studies showed the role of Hsa-miR-490 as potential drug resistance in ovarian cancer [147] and as a potential novel biomarker for diagnosing of colorectal cancer [148].

Down regulation of Hsa-miR-429 was highlighted in the 3D culture-specific miRNA profile better than that in the 2D culture-specific profile, by correlating with the 3D invasive capacity of the MDA-MB-231 BC cell line [149].

Hsa-miR-429 could be also a regulator of HIF1 Signalling, Glioblastoma Multiforme, Acute Phase Response Signalling and HIF1 Signalling.

\section{HIF1 signalling and glioblastoma multiforme signalling regulated by Hsa-miR-190b, Hsa-miR-1246, Hsa-miR-429}

The role of HIF1 Signalling in cancer has already been mentioned above. As regards Glioblastoma multiforme Signalling pathway, among all the altered genes in common with HIF1 Signalling pathway, the main genes are those of the Ras family (i.e., KRas and NRas), already found mutated in triple-negative $\mathrm{BC}$ [150], the genes of the PI3K pathway (i.e., PIK3C3, PIK3CA), which has been already found silenced or mutated in aggressive $\mathrm{BC}$ $[151,152]$, and those of the serine/threonine protein 
kinase family, like ATM, already associated with hormone negative early stage BC [153].

As regards miRNAs able to regulate these couples of pathways, we identified Hsa-miR-429 (already described above), Hsa-miR-190b and Hsa-miR-1246. Hsa-miR$190 b$ is indicated as a higher discriminating miRNA between ER+ and ER- BC. This miRNA has also an impact on metastasis-free survival and event-free survival rates, independently of ER status [154]. Hsa-miR-1246 was included in a 5-miRNA signature with good diagnostic features, able to discriminate between healthy and early stage BC samples [155].

\section{Acute phase response signalling and HIF1 Signalling regulated by Hsa-miR-429, Hsa-miR-3617}

The role of HIF1 Signalling in cancer has already been mentioned above. Acute Phase Response Signalling has a clear role in both ER+ and triple negative BC [156]. Looking to the genes involved in Acute Phase Response Signalling in common with those of HIF1 Signalling, they belong to the MAP kinase pathway (i.e. MAPK8, MAPK14) or to the RAS protein family (i.e. NRas), as discussed above. Hsa-miR-429 has already been discussed. As regards Hsa-miR-3617, no publication is currently available about the function of this miRNA in any biological processes.

\section{Atherosclerosis signalling and acute phase response signalling regulated by Hsa-miR-1910}

The Acute Phase Response Signalling plays a clear role in BC, as already mentioned. There are only a few publications that associate Atherosclerosis Signalling to BC. However, one of the main molecule involved in tissue remodelling and in atherosclerosis is tenascin-C. Its serum level of expression has no predictive or prognostic ability in $\mathrm{BC}$, although it is elevated in $\mathrm{BC}$ patients [157]. As regards miRNAs involved in the control of this couple of pathways, we identified a single miRNA, Hsa$m i R-1910$. This miRNA is included in a group of $8 \mathrm{miR}-$ NAs, whose silencing by methylation leads to the onset of BC [158].

\section{Conclusions}

We identified pairwise pathways for $\mathrm{BC}$ subtypes able to discriminate $\mathrm{BC}$ vs. normal samples. From these pairs, we created a network of pathways specific for each subtype. Following an enrichment analysis, we focused on miRNAs with an important role in the regulation of the network.

In the network of pathways for $\mathrm{BC}$ luminal $\mathrm{A}$, we found 11 miRNAs: Hsa-miR-1-1, Hsa-miR-1250, Hsa-miR-1537, Hsa-miR-205, Hsa-miR-210, Hsa-miR-3199-1, Hsa-miR335, Hsa-miR-337, Hsa-miR-381, Hsa-miR-452, and HsamiR-99a. Among them, Hsa-miR-210, and Hsa-miR-205 have a potential therapeutic role, acting as biomarkers of the response to trastuzumab, and to neoadjuvant chemotherapy, respectively.

In the network of pathways for $\mathrm{BC}$ luminal $\mathrm{B}$, we found 3 miRNAs: Hsa-miR-32, Hsa-miR-3074, and HsamiR-577. Among them, Hsa-miR-32 has been already associated with cancer progression.

In the network of pathways for $\mathrm{BC}$ basal we found 2 miRNAs: Hsa-miR-135b, and Hsa-miR-365-2. Among them, Hsa-miR-365-2 showed an apoptotic role and could play a therapeutic role.

In the network of pathways for HER2 BC, we found 14 miRNAs: Hsa-miR-1246, Hsa-miR-142, Hsa-miR-148b, Hsa-miR-155, Hsa-miR-190, Hsa-miR-190b, Hsa-miR1910, Hsa-miR-3617, Hsa-miR-429, Hsa-miR-449c, HsamiR-490, Hsa-miR-511-2, Hsa-miR-584, Hsa-miR-92b. Among them, Hsa-miR-148b, Hsa-miR-92b, Hsa-miR142, Hsa-miR-155 are interesting for drug design, as a role in the response to different therapeutic strategies has been already described.

The identification of a network of dependent pathways and their regulatory miRNAs is a current challenge in order to have an overview of a complex disease such as cancer. In particular, miRNAs, once validated in a laboratory assay, could be suitable for translation to a clinical environment. The low-cost procedures and the possibility to be measured by non-invasive tests make miRNAs important diagnostic and therapeutic tools for further studies.

\section{Additional files}

Additional file 1: miRNA-r for each pairwise pathway and gene target in luminal A. (DOCX $16 \mathrm{~kb}$ )

Additional file 2: miRNA-r for each pairwise pathway and gene target in luminal B. (DOCX $11 \mathrm{~kb})$

Additional file 3: miRNA-r for each pairwise pathway and gene target in Basal. (DOCX $11 \mathrm{~kb}$ )

Additional file 4: miRNA-r for each pairwise pathway and gene target in HER2. (DOCX $16 \mathrm{~kb}$ )

\section{Acknowledgments \\ The authors would like to thank for the financial support: INTEROMICS flagship project (http://www.interomics.eu/it/home), National Research Council CUP Grant B91J12000190001, and the project grant SysBioNet, Italian Roadmap Research Infrastructures 2012.}

\section{Declarations}

This article has been published as part of BMC Bioinformatics Vol 17 Suppl 12 2016: Italian Society of Bioinformatics (BITS): Annual Meeting 2015. The full contents of the supplement are available online at http:// bmcbioinformatics.biomedcentral.com/articles/supplements/volume-17supplement-12.

\section{Funding}

Publication of this article has been funded by a research project INTEROMICS flagship (http://www.interomics.eu/it/home), National Research Council CUP Grant B91J12000190001, and by the project grant SysBioNet, Italian Roadmap Research Infrastructures 2012. 


\section{Availability of data and materials}

Not applicable.

\section{Authors' contributions}

Conceived and designed the experiments: CC AC GB GB IC. Performed the experiments: CC AC. Analyzed the data: CC GB. Wrote the paper: CC GB IC GB GM. All authors read and approved the final manuscript.

\section{Competing interests}

The authors declare that they have no competing interests.

\section{Consent for publication}

Not applicable.

\section{Ethics approval and consent to participate}

Not applicable.

\section{Author details}

${ }^{1}$ Institute of Molecular Bioimaging and Physiology (IBFM), National Research Council (CNR), Milan, Italy. ${ }^{2}$ Interuniversity Institute of Bioinformatics in Brussels (IB), Brussels, Belgium. ${ }^{3}$ Machine Learning Group, ULB, Brussels, Belgium. ${ }^{4}$ Department of Informatics, Systems and Communications, University of Milan-Bicocca, Milan, Italy.

\section{Published: 8 November 2016}

\section{References}

1. Cava C, Bertoli G, Ripamonti M, Mauri G, Zoppis I, Della Rosa PA, Gilardi MC, Castiglioni I. Integration of mRNA expression profile, copy number alterations, and microRNA expression levels in breast cancer to improve grade definition. PLoS One. 2014;9(5):e97681.

2. Sotiriou C, Wirapati P, Loi S, Harris A, Fox S, Smeds J, Nordgren H, Farmer P, Praz V, Haibe-Kains B, Desmedt C, Larsimont D, Cardoso F, Peterse H, Nuyten D, Buyse M, Van de Vijver MJ, Bergh J, Piccart M, Delorenzi M. Gene expression profiling in breast cancer: understanding the molecular basis of histologic grade to improve prognosis. J Natl Cancer Inst. 2006;98(4):262-72.

3. Miller PC, Clarke J, Koru-Sengul T, Brinkman J, El-Ashry D. A novel MAPKmicroRNA signature is predictive of hormone-therapy resistance and poor outcome in ER-positive breast cancer. Clin Cancer Res. 2015;21 (2):373-85.

4. Cava C, Zoppis I, Mauri G, Ripamonti M, Gallivanone F, Salvatore C, Gilardi MC, Castiglioni I. Combination of gene expression and genome copy number alteration has a prognostic value for breast cancer. Conf Proc IEEE Eng Med Biol Soc. 2013;2013:608-11.

5. Cava C, Zoppis I, Gariboldi M, Castiglioni I, Mauri G, Antoniotti M. Copynumber alterations for tumor progression inference. Artificial Intelligence in Medicine Volume 7885 of the series Lecture Notes in Computer Science, 2013 pp. 104-109.

6. Perou CM, Sørlie T, Elsen MB, van de Rijn M, Jeffrey SS, Rees CA, et al. Molecular portraits of human breast tumours. Nature. 2000;406:747-52.

7. Sørlie T, Perou CM, Tibshirani R, Aas T, Geisler S, Johnsen H, et al. Gene expression patterns of breast carcinomas distinguish tumor subclasses with clinical implications. Proc Natl Acad Sci U S A. 2001;98:10869-74.

8. Cheang MC, Chia SK, Voduc D, Gao D, Leung S, Snider J, Watson M, Davies S, Bernard PS, Parker JS. Ki67 index, HER2 status, and prognosis of patients with luminal B breast cancer. J Natl Cancer Inst. 2009;101:736-50.

9. Dowsett M, Nielsen TO, A'Hern R, Bartlett J, Coombes RC, Cuzick J, Ellis M, Henry NL, Hugh JC, Lively T, McShane L, Paik S, Penault-Llorca F, Prudkin L, Regan M, Salter J, Sotiriou C, Smith IE, Viale G, Zujewski JA, Hayes DF, International Ki-67 in Breast Cancer Working Group. Assessment of Ki67 in breast cancer: recommendations from the International Ki67 in Breast Cancer working group. J Natl Cancer Inst. 2011;16:1656-64.

10. Carey LA, Perou CM, Livasy CA, Dressler LG, Cowan D, et al. Race, breast cancer subtypes, and survival in the Carolina Breast Cancer Study. JAMA. 2006;295:2492-502.

11. O'Brien KM, Cole SR, Tse CK, Perou CM, Carey LA, et al. Intrinsic breast tumor subtypes, race, and long-term survival in the Carolina Breast Cancer Study. Clin Cancer Res. 2010;16:6100-10.

12. Iyer SV, Dange PP, Alam H, Sawant SS, Ingle AD, Borges AM, Shirsat NV, Dalal SN, Vaidya MM. Understanding the role of keratins 8 and 18 in neoplastic potential of breast cancer derived cell lines. PLoS One. 2013; 8(1):e53532.
13. Xu C, Wei Q, Guo J, Zhou JC, Mei J, Jiang ZN, Shen JG, Wang LB. FOXA1 Expression Significantly Predict Response to Chemotherapy in Estrogen Receptor-Positive Breast Cancer Patients. Ann Surg Oncol. 2015;22(6):2034-9.

14. Sørlie T. Molecular portraits of breast cancer: tumour subtypes as distinct disease entities. Eur J Cancer. 2004;40:2667-75.

15. Paik S, Shak S, Tang G, Kim C, Baker J, Cronin M, Baehner FL, Walker MG Watson D, Park T. A multigene assay to predict recurrence of tamoxifentreated, node-negative breast cancer. N Engl J Med. 2004;351:2817-26.

16. Rouzier R, Perou CM, Symmans WF, Ibrahim N, Cristofanilli M, Anderson K, Hess KR, Stec J, Ayers M, Wagner P. Breast cancer molecular subtypes respond differently to preoperative chemotherapy. Clin Cancer Res. 2005;11: 5678-85.

17. Bhargava R, Beriwal S, Dabbs DJ, Ozbek U, Soran A, Johnson RR, Brufsky AM, Lembersky BC, Ahrendt GM. Immunohistochemical surrogate markers of breast cancer molecular classes predicts response to neoadjuvant chemotherapy: a single institutional experience with 359 cases. Cancer. 2010;116:1431-9.

18. Reis-Filho JS, Weigelt B, Fumagalli D, Sotiriou C. Molecular profiling: moving away from tumor philately. Sci Transl Med. 2010;2(47):47ps43.

19. Tran B, Bedard PL. Luminal-B breast cancer and novel therapeutic targets. Breast Cancer Res. 2011;13(6):221.

20. Peyrat JP, Bonneterre J, Helquet B, Vennin P, Louchez MM, Fournier C, Lefebvre J, Demaille A. Plasma insulin-like growth factor-1 (IGF-1) concentrations in human breast cancer. Eur J Cancer. 1993;29A:492-7.

21. Casanovas O, Hicklin DJ, Bergers G, Hanahan D. Drug resistance by evasion of antiangiogenic targeting of VEGF Signalling in late-stage pancreatic islet tumors. Cancer Cell. 2005;8:299-309.

22. Presta M, Dell'Era P, Mitola S, Moroni E, Ronca R, Rusnati M. Fibroblast growth factor/fibroblast growth factor receptor system in angiogenesis. Cytokine Growth Factor Rev. 2005;16:159-78.

23. Turner N, Pearson A, Sharpe R, Lambros M, Geyer F, Lopez-Garcia MA, Natrajan R, Marchio C, lorns E, Mackay A, Gillett C, Grigoriadis A, Tutt A, Reis-Filho JS, Ashworth A. FGFR1 amplification drives endocrine therapy resistance and is a therapeutic target in breast cancer. Cancer Res. 2010; 70:2085-94

24. Shiang CY, Qi Y, Wang B, Lazar V, Wang J, Fraser Symmans W, Hortobagyi GN, Andre F, Pusztai L. Amplification of fibroblast growth factor receptor-1 in breast cancer and the effects of brivanib alaninate. Breast Cancer Res Treat. 2009;123:747-55.

25. Fox EM, Kuba MG, Miller TW, Davies BR, Arteaga CL. Autocrine IGF-I/insulin receptor axis compensates for inhibition of AKT in ER-positive breast cancer cells with resistance to estrogen deprivation. Breast Cancer Res. 2013;15(4):R55.

26. Atzori F, Traina TA, lonta MT, Massidda B. Targeting insulin-like growth factor type 1 receptor in cancer therapy. Target Oncol. 2009;4:255-66.

27. Creighton CJ, Fu X, Hennessy BT, Casa AJ, Zhang Y, Gonzalez-Angulo AM, Lluch A, Gray JW, Brown PH, Hilsenbeck SG, Osborne CK, Mills GB, Lee AV, $S$ chiff R. Proteomic and transcriptomic profiling reveals a link between the $\mathrm{PI} 3 \mathrm{~K}$ pathway and lower estrogen-receptor (ER) levels and activity in $\mathrm{ER}^{+}$ breast cancer. Breast Cancer Res. 2010;12:R40.

28. Heitz F, Harter P, Lueck HJ, Fissler-Eckhoff A, Lorenz-Salehi F, Scheil-Bertram S, Traut A, du Bois A. Triple-negative and HER2-overexpressing breast cancers exhibit an elevated risk and an earlier occurrence of cerebral metastases. Eur J Cancer. 2009;45:2792-8.

29. Sorlie T, Tibshirani R, Parker J, Hastie T, Marron JS, Nobel A, et al. Repeated observation of breast tumor subtypes in independent gene expression data sets. Proc Natl Acad Sci U S A. 2003;100:8418-23.

30. Foulkes WD, Stefansson IM, Chappuis PO, Bégin LR, Goffin JR, Wong N, et al. Germline BRCA1 mutations and a basal epithelial phenotype in breast cancer. J Natl Cancer Inst. 2003;95:1482-5.

31. De Summa S, Pinto R, Sambiasi D, Petriella D, Paradiso V, Paradiso A, et al. BRCAness: a deeper insight into basal-like breast tumors. Ann Oncol. 2013 24 Suppl 8:viii13-21.

32. Anders CK, Carey LA. Biology, metastatic patterns, and treatment of patients with triple-negative breast cancer. Clin Breast Cancer. 2009;9 Suppl 2:573-81.

33. Toft DJ, Cryns VL. Minireview: Basal-like breast cancer: from molecular profiles to targeted therapies. Mol Endocrinol. 2011;25(2):199-211.

34. Ivy SP, Wick JY, Kaufman BM. An overview of small-molecule inhibitors of VEGFR Signalling. Nat Rev Clin Oncol. 2009;6:569-79.

35. Guix M, Granja Nde M, Meszoely I, Adkins TB, Wieman BM, Frierson KE, Sanchez V, Sanders ME, Grau AM, Mayer IA, Pestano G, Shyr Y, 
Muthuswamy S, Calvo B, Krontiras H, Krop IE, Kelley MC, Arteaga CL. Short preoperative treatment with erlotinib inhibits tumor cell proliferation in hormone receptor-positive breast cancers. J Clin Oncol. 2008;26:897-906

36. Yersal O, Barutca S. Biological subtypes of breast cancer: Prognostic and therapeutic implications. World J Clin Oncol. 2014;5(3):412-24.

37. Wu VS, Kanaya N, Lo C, Mortimer J, Chen S. From bench to bedside: What do we know about hormone receptor-positive and human epidermal growth factor receptor 2-positive breast cancer? I Steroid Biochem Mol Biol. 2015;153:45-53.

38. Benz CC, Scott GK, Sarup JC, Johnson RM, Tripathy D, Coronado E, Shepard HM, Osborne CK. Estrogen-dependent, tamoxifen-resistant tumorigenic growth of MCF-7 cells transfected with HER2/neu. Breast Cancer Res Treat. 1992:24(2):85-95.

39. Colaprico A, Cava C, Bertoli G, Bontempi G, Castiglioni I. Integrative Analysis with Monte Carlo Cross-Validation Reveals miRNAs Regulating Pathways Cross-Talk in Aggressive Breast Cancer. Biomed Res Int. 2015;2015:831314.

40. Huang S, Yee C, Ching T, Yu H, Garmire LX. A novel model to combine clinical and pathway-based transcriptomic information for the prognosis prediction of breast cancer. PLoS Comput Biol. 2014;10(9):e1003851.

41. Bild AH, Yao G, Chang JT, Wang Q, Potti A, et al. Oncogenic pathway signatures in human cancers as a guide to targeted therapies. Nature. 2006; 439:353-7.

42. van den Akker EB, Passtoors WM, Jansen R, van Zwet EW, Goeman JJ, et al. Meta-analysis on blood transcriptomic studies identifies consistently coexpressed protein-protein interaction modules as robust markers of human aging. Aging Cell. 2013;13:216-25.

43. Saini KS, Loi S, de Azambuja E, Metzger-Filho O, Saini ML, Ignatiadis M, Dancey JE, Piccart-Gebhart MJ. Targeting the PI3K/AKT/mTOR and Raf/MEKJ ERK pathways in the treatment of breast cancer. Cancer Treat Rev. 2013; 39(8):935-46.

44. Guo S, Liu M, Gonzalez-Perez RR. Role of Notch and its oncogenic Signalling crosstalk in breast cancer. Biochim Biophys Acta. 2011;1815(2):197-213.

45. Madak-Erdogan Z, Lupien M, Stossi F, Brown M, Katzenellenbogen BS. Genomic collaboration of estrogen receptor alpha and extracellular signalregulated kinase 2 in regulating gene and proliferation programs. Mol Cell Biol. 2011;31(1):226-36.

46. van Vliet MH, Horlings HM, van de Vijver MJ, Reinders MJ, Wessels LF. Integration of clinical and gene expression data has a synergetic effect on predicting breast cancer outcome. PLoS One. 2012;7:e40358.

47. Ma S, Kosorok MR, Huang J, Dai Y. Incorporating higher-order representative features improves prediction in network-based cancer prognosis analysis. BMC Med Genomics. 2011:4:5.

48. Abraham G, Kowalczyk A, Loi S, Haviv I, Zobel J. Prediction of breast cancer prognosis using gene set statistics provides signature stability and biological context. BMC Bioinformatics. 2010;11:277.

49. Kessler T, Hache H, Wierling C. Integrative analysis of cancer-related Signalling pathways. Front Physiol. 2013:4:124.

50. Ventura A, Jacks T. MicroRNAs and cancer: short RNAs go a long way. Cell. 2009:136:586-91.

51. Volinia S, Calin GA, Liu CG, Ambs S, Cimmino A, Petrocca F, et al. A microRNA expression signature of human solid tumors defines cancer gene targets. Proc Natl Acad Sci USA. 2006;103:2257-61.

52. Tavazoie SF, Alarcon C, Oskarsson T, Padua D, Wang Q, Bos PD, et al. Endogenous human microRNAs that suppress breast cancer metastasis. Nature. 2008:451:147-52.

53. Sun X, Jiao X, Pestell TG, et al. MicroRNAs and cancer stem cells: the sword and the shield. Oncogene. 2014;33:4967-77.

54. Li H, Bian C, Liao L, et al. miR-17-5p promotes human breast cancer cell migration and invasion through suppression of HBP1. Breast Cancer Res Treat. 2011;126:565-75.

55. Piva R, Spandidos DA, Gambari R. From microRNA functions to microRNA therapeutics: novel targets and novel drugs in breast cancer research and treatment (Review). Int J Oncol. 2013;43:985-94.

56. Christodoulatos GS, Dalamaga M. Micro-RNAs as clinical biomarkers and therapeutic targets in breast cancer: Quo vadis? World J Clin Oncol. 2014; 5:71-81.

57. Fassan M, Pizzi M, Realdon S, et al. The HER2-miR125a5p/miR125b loop in gastric and esophageal carcinogenesis. Hum Pathol. 2013;44:1804-10.

58. Mattie MD, Benz CC, Bowers J, et al. Optimized high-throughput microRNA expression profiling provides novel biomarker assessment of clinical prostate and breast cancer biopsies. Mol Cancer. 2006;5:24.
59. Scott GK, Goga A, Bhaumik D, et al. Coordinate suppression of ERBB2 and ERBB3 by enforced expression of micro-RNA miR-125a or miR-125b. J Biol Chem. 2007;282:1479-86.

60. Yun J, Frankenberger CA, Kuo WL, et al. Signalling pathway for RKIP and Let-7 regulates and predicts metastatic breast cancer. EMBO J. 2011;30: 4500-14.

61. Kondo N, Toyama T, Sugiura H, et al. miR-206 Expression is down-regulated in estrogen receptor alpha-positive human breast cancer. Cancer Res. 2008;68:5004-8.

62. Li Y, Hong F, Yu Z. Decreased expression of microRNA-206 in breast cancer and its association with disease characteristics and patient survival. J Int Med Res. 2013;41:596-602.

63. Elliman SJ, Howley BV, Mehta DS, et al. Selective repression of the oncogene cyclin D1 by the tumor suppressor miR-206 in cancers. Oncogenesis. 2014;3:e113.

64. Adams BD, Furneaux H, White BA. The micro-ribonucleic acid (NA) miR-206 targets the human estrogen receptor-alpha (ERalpha) and represses ERalpha messenger RNA and protein expression in breast cancer cell lines. Mol Endocrinol. 2007;21:1132-47.

65. Colaprico A, Silva TC, Olsen C, Garofano L, Cava C, Garolini D, Sabedot TS, Malta TM, Pagnotta SM, Castiglioni I, Ceccarelli M, Bontempi G, Noushmehr H. TCGAbiolinks: an R/Bioconductor package for integrative analysis of TCGA data. Nucleic Acids Res. 2016:44(8):e71.

66. Benjamini Y, Hochberg Y. Controlling the false discovery rate: a practical and powerful approach to multiple testing. J Royal Stat Soc Series B (Methodological). 1995;57(1):289-300.

67. Liaw A, Wiener M. Classification and regression by randomForest. R news. 2002;2(3):18-22.

68. Kraskov A, Stogbauer H, Grassberger P. Estimating mutual information. Physical review E. 2004;69(6):066138.

69. Sales $G$, Romualdi C. parmigene-a parallel R package for mutual information estimation and gene network reconstruction. Bioinformatics. 2011;27(13):1876-7.

70. Falanga A, Levine MN, Consonni R, Gritti G, Delaini F, Oldani E, Julian JA, Barbui T. The effect of very-low-dose warfarin on markers of hypercoagulation in metastatic breast cancer: results from a randomized trial. Thromb Haemost. 1998;79(1):23-7.

71. Yang Z, Han Y, Cheng K, Zhang G, Wang X. miR-99a directly targets the Mtor signalling pathway in breast cancer side population cells. Cell Prolif. 2014:47(6):587-95.

72. Sun EH, Zhou Q, Liu KS, Wei W, Wang CM, Liu XF, Lu C, Ma DY. Screening miRNAs related to different subtypes of breast cancer with miRNAs microarray. Eur Rev Med Pharmacol Sci. 2014;18(19):2783-8.

73. Liu J, Mao Q, Liu Y, Hao X, Zhang S, Zhang J. Analysis of miR-205 and miR155 expression in the blood of breast cancer patients. Chin J Cancer Res. 2013;25(1):46-54.

74. Li M, Ma X, Li M, Zhang B, Huang J, Liu L, Wei Y. Prognostic role of microRNA-210 in various carcinomas: a systematic review and meta-analysis. Dis Markers. 2014:2014:106197.

75. Jung EJ, Santarpia L, Kim J, Esteva FJ, Moretti E, Buzdar AU, Di Leo A, Le XF, Bast Jr RC, Park ST, Pusztai L, Calin GA. Plasma microRNA 210 levels correlate with sensitivity to trastuzumab and tumor presence in breast cancer patients. Cancer. 2012;118(10):2603-14.

76. Voigtländer T, Gupta SK, Thum S, Fendrich J, Manns MP, Lankisch TO, Thum T. MicroRNAs in Serum and Bile of Patients with Primary Sclerosing Cholangitis and/or Cholangiocarcinoma. PLoS One. 2015;10(10):e0139305. doi:10.1371/journal.pone.0139305

77. Davalieva K, Kiprijanovska S, Komina S, Petrusevska G, Zografska NC, Polenakovic M. Proteomics analysis of urine reveals acute phase response proteins as candidate diagnostic biomarkers for prostate cancer. Proteome Sci. 2015;13(1):2.

78. Eltzschig HK, Carmeliet P. Hypoxia and inflammation. New England Journal of Medicine. 2011;364(7):656-65.

79. Piovan C, Palmieri D, Di Leva G, Braccioli L, Casalini P, Nuovo G, Tortoreto M, Sasso M, Plantamura I, Triulzi T, Taccioli C, Tagliabue E, lorio MV, Croce CM. Oncosuppressive role of p53-induced miR-205 in triple negative breast cancer. Mol Oncol. 2012;6(4):458-72.

80. Sempere LF, Christensen M, Silahtaroglu A, Bak M, Heath CV, Schwartz G, Wells W, Kauppinen S, Cole CN. Altered MicroRNA expression confined to specific epithelial cell subpopulations in breast cancer. Cancer Res. 2007; 67(24):11612-20. 
81. Elgamal OA, Park JK, Gusev Y, Azevedo-Pouly AC, Jiang J, Roopra A, Schmittgen TD. Tumor suppressive function of mir-205 in breast cancer is linked to HMGB3 regulation. PLoS One. 2013;8(10):e76402.

82. Mehlen P, Delloye-Bourgeois C, Chédotal A. Novel roles for Slits and netrins: axon guidance cues as anticancer targets? Nat Rev Cancer. 2011;11(3):188-97.

83. Li Q, Liu M, Ma F, Luo Y, Cai R, Wang L, Xu N, Xu B. Circulating miR-19a and miR-205 in serum may predict the sensitivity of luminal A subtype of breast cancer patients to neoadjuvant chemotherapy with epirubicin plus paclitaxel. PLoS One. 2014;9(8):e104870.

84. Polytarchou C, lliopoulos D, Struhl K. An integrated transcriptional regulatory circuit that reinforces the breast cancer stem cell state. Proc Natl Acad Sci U S A. 2012;109:14470-5.

85. Andorfer CA, Necela BM, Thompson EA, Perez EA. MicroRNA signatures: clinical biomarkers for the diagnosis and treatment of breast cancer. Trends Mol Med. 2011:17:313-9.

86. Lynch J, Fay J, Meehan M, Bryan K, Watters KM, Murphy DM, Stallings RL. MiRNA-335 suppresses neuroblastoma cell invasiveness by direct targeting of multiple genes from the non-canonical TGF- $\beta$ signalling pathway. Carcinogenesis. 2012;33(5):976-85.

87. Wang Z, Wang J, Yang Y, Hao B, Wang R, Li Y, Wu Q. Loss of has-miR-337$3 p$ expression is associated with lymph node metastasis of human gastric cancer. J Exp Clin Cancer Res. 2013;32:76.

88. Medina-Villaamil V, Martínez-Breijo S, Portela-Pereira P, Quindós-Varela M, Santamarina-Caínzos I, Antón-Aparicio LM, Gómez-Veiga F. Circulating MicroRNAs in blood of patients with prostate cancer. Actas Urol Esp. 2014; 38(10):633-9.

89. Hu Q, Gong JP, Li J, Zhong SL, Chen WX, Zhang JY, Ma TF, Ji H, LV MM, Zhao JH, Tang JH. Down-regulation of miRNA-452 is associated with adriamycin-resistance in breast cancer cells. Asian Pac J Cancer Prev. 2014; 15(13):5137-42.

90. Hu Q, Chen WX, Zhong SL, Zhang JY, Ma TF, Ji H, Lv MM, Tang JH, Zhao JH. MicroRNA-452 contributes to the docetaxel resistance of breast cancer cells. Tumour Biol. 2014;35(7):6327-34.

91. de Faria Jr O, Cui QL, Bin JM, Bull SJ, Kennedy TE, Bar-Or A, Antel JP, Colman DR, Dhaunchak AS. Regulation of miRNA 219 and miRNA Clusters 338 and 17-92 in Oligodendrocytes. Front Genet. 2012;3:46. doi:10.3389/fgene.2012. 00046. eCollection 2012. PubMed PMID: 22470405.

92. Marcato P, Dean CA, Giacomantonio CA, Patrick WK L. Aldehyde dehydrogenase: its role as a cancer stem cell marker comes down to the specific isoform. Cell Cycle. 2011;10(9):1378-84.

93. Honeth G, Lombardi S, Ginestier C, Hur M, Marlow R, Buchupalli B, Shinomiya I, Gazinska P, Bombelli S, Ramalingam V, Purushotham AD, Pinder SE, Dontu G. Aldehyde dehydrogenase and estrogen receptor define a hierarchy of cellular differentiation in the normal human mammary epithelium. Breast Cancer Res. 2014;16(3):R52.

94. Ali HR, Dawson SJ, Blows FM, Provenzano E, Pharoah PD, Caldas C. Cancer stem cell markers in breast cancer: pathological, clinical and prognostic significance. Breast Cancer Res. 2011;13(6):R118.

95. Khoury T, Ademuyiwa FO, Chandrasekhar R, Jabbour M, Deleo A, Ferrone S, Wang $Y$, Wang $X$. Aldehyde dehydrogenase $1 \mathrm{~A} 1$ expression in breast cancer is associated with stage, triple negativity, and outcome to neoadjuvant chemotherapy. Mod Pathol. 2012;25(3):388-97.

96. Talhouk R. On cell-matrix interactions in mammary gland development and breast cancer. Cold Spring Harb Perspect Biol. 2012;4(8):a013540. doi:10. 1101/cshperspect.a013540.

97. Troeger A, Johnson AJ, Wood J, Blum WG, Andritsos LA, Byrd JC, Williams DA. RhoH is critical for cell-microenvironment interactions in chronic lymphocytic leukemia in mice and humans. Blood. 2012;119(20):4708-18. doi:10.1182/blood-2011-12-395939.

98. Dart AE, Box GM, Court W, Gale ME, Brown JP, Pinder SE, Eccles SA, Wells CM. PAK4 promotes kinase-independent stabilization of RhoU to modulate cell adhesion. J Cell Biol. 2015;211(4):863-79. doi:10.1083/jcb.201501072.

99. Ma CX, Crowder RJ, Ellis MJ. Importance of PI3-kinase pathway in response/ resistance to aromatase inhibitors. Steroids. 2011;76(8):750-2. doi:10.1016/j. steroids.2011.02.023. Epub 2011 Mar 21.

100. Zhou Z, Qiao JX, Shetty A, Wu G, Huang Y, Davidson NE, Wan Y. Regulation of estrogen receptor Signalling in breast carcinogenesis and breast cancer therapy. Cell Mol Life Sci. 2014;71(8):1549. doi:10.1007/s00018-013-1376-3. Retraction in: Cell Mol Life Sci. 2014 Apr;71(8):1549.

101. Han C, Yu Z, Duan Z, Kan Q. Role of microRNA-1 in human cancer and its therapeutic potentials. Biomed Res Int. 2014;2014:428371.
102. Reid JF, Sokolova V, Zoni E, Lampis A, Pizzamiglio S, Bertan C, Zanutto S, Perrone F, Camerini T, Gallino G, Verderio P, Leo E, Pilotti S, Gariboldi M, Pierotti MA. miRNA profiling in colorectal cancer highlights miR-1 involvement in MET-dependent proliferation. Mol Cancer Res. 2012;10(4):504-15.

103. Pavlakis K, Bobos M, Batistatou A, Kotoula V, Eleftheraki AG, Stofas A, Timotheadou E, Pentheroudakis G, Psyrri A, Koutras A, Pectasides D, Papakostas P, Razis E, Christodoulou C, Kalogeras KT, Fountzilas G. p85 protein expression is associated with poor survival in HER2-positive patients with advanced breast cancer treated with trastuzumab. Pathol Oncol Res. 2015;21(2):273-82. doi:10.1007/s12253-014-9818-2.

104. Brendle A, Lei H, Brandt A, Johansson R, Enquist K, Henriksson R, Hemminki $K$, Lenner $P$, Försti A. Polymorphisms in predicted microRNA-binding sites in integrin genes and breast cancer: ITGB4 as prognostic marker. Carcinogenesis. 2008;29(7):1394-9. doi:10.1093/carcin/bgn126.

105. Shih W, Yamada S. N-cadherin-mediated cell-cell adhesion promotes cell migration in a three-dimensional matrix. J Cell Sci. 2012;125(Pt15):3661-70.

106. Calin GA, Sevignani C, Dumitru CD, Hyslop T, Noch E, et al. Human microRNA genes are frequently located at fragile sites and genomic regions involved in cancers. Proc Natl Acad Sci U S A. 2004;101:2999-3004.

107. Wu W, Yang J, Feng $X$, Wang H, Ye S, Yang P, Tan W, Wei G, Zhou Y. MicroRNA-32 (miR-32) regulates phosphatase and tensin homologue (PTEN) expression and promotes growth, migration, and invasion in colorectal carcinoma cells. Mol Cancer. 2013;12:30.

108. Ge YZ, Xu LW, Xu Z, Wu R, Xin H, Zhu M, Lu TZ, Geng LG, Liu H, Zhou CC, Yu P, Zhao YC, Hu ZK, Zhao Y, Zhou LH, Wu JP, Li WC, Zhu JG, Jia RP. Expression Profiles and Clinical Significance of MicroRNAs in Papillary Renal Cell Carcinoma: A STROBE-Compliant Observational Study. Medicine (Baltimore). 2015;94(16):e767. doi:10.1097/MD.0000000000000767.

109. Zhang W, Shen C, Li C, Yang G, Liu H, Chen X, Zhu D, Zou H, Zhen Y, Zhang D, Zhao S. miR-577 inhibits glioblastoma tumor growth via the Wnt Signalling pathway. Mol Carcinog. 2015 Mar 12. doi: 10.1002/mc.22304

110. Wang LY, Li B, Jiang HH, Zhuang LW, Liu Y. Inhibition effect of miR-577 on hepatocellular carcinoma cell growth via targeting $\beta$-catenin. Asian Pac J Trop Med. 2015;8(11):923-9. doi:10.1016/j.apjtm.2015.10.001.

111. Yuan X, He J, Sun F, Gu J. Effects and interactions of MiR-577 and TSGA10 in regulating esophageal squamous cell carcinoma. Int J Clin Exp Pathol. 2013; 6(12):2651-67.

112. Li GM. Mechanisms and functions of DNA mismatch repair. Cell Res. 2008; 18(1):85-98.

113. Lowery AJ, Miller N, Devaney A, et al. MicroRNA signatures predict estrogen receptor, progesterone receptor and HER2/neu receptor status in breast cancer. Breast Cancer Res. 2009;11:R27.

114. Valeri N, Braconi C, Gasparini P, Murgia C, Lampis A, Paulus-Hock V, Hart JR, Ueno L, Grivennikov SI, Lovat F, Paone A, Cascione L, Sumani KM, Veronese A, Fabbri M, Carasi S, Alder H, Lanza G, Gafa' R, Moyer MP, Ridgway RA, Cordero J, Nuovo GJ, Frankel WL, Rugge M, Fassan M, Groden J, Vogt PK, Karin M, Sansom OJ, Croce CM. MicroRNA-135b promotes cancer progression by acting as a downstream effector of oncogenic pathways in colon cancer. Cancer Cell. 2014;25(4):469-83.

115. Lessard M, Zhao C, Singh SM, Poulin R. Hormonal and feedback regulation of putrescine and spermidine transport in human breast cancer cells. J Biol Chem. 1995;270(4):1685-94.

116. Igarashi K, Kashiwagi K. Modulation of cellular function by polyamines. Int J Biochem Cell Biol. 2010;42(1):39-51.

117. Singh R, Saini N. Downregulation of BCL2 by miRNAs augments druginduced apoptosis-a combined computational and experimental approach. J Cell Sci. 2012;125(Pt 6):1568-78.

118. Hamada S, Masamune A, Miura S, Satoh K, Shimosegawa T. MiR-365 induces gemcitabine resistance in pancreatic cancer cells by targeting the adaptor protein SHC1 and pro-apoptotic regulator BAX. Cell Signal. 2014; 26(2):179-85.

119. Gasparri AM, Jachetti E, Colombo B, Sacchi A, Curnis F, Rizzardi GP, Traversari C, Bellone M, Corti A. Critical role of indoleamine 2,3-dioxygenase in tumor resistance to repeated treatments with targeted IFNgamma. Mol Cancer Ther. 2008;7:3859-66.

120. Kim WT, Yun SJ, Yan C, Jeong P, Kim YH, Lee IS, Kang HW, Park S, Moon SK, Choi YH, Choi YD, Kim IY, Kim J, Kim WJ. Metabolic Pathway Signatures Associated with Urinary Metabolite Biomarkers Differentiate Bladder Cancer Patients from Healthy Controls. Yonsei Med J. 2016;57(4):865-71.

121. Koblish HK, Hansbury MJ, Bowman KJ, Yang G, Neilan CL, Haley PJ, Burn TC, Waeltz P, Sparks RB, Yue EW, Combs AP, Scherle PA, Vaddi K, Fridman JS. 
Hydroxyamidine inhibitors of indoleamine-2,3-dioxygenase potently suppress systemic tryptophan catabolism and the growth of IDO-expressing tumors. Mol Cancer Ther. 2010;9(2):489-98.

122. Uyttenhove C, Pilotte L, Théate I, Stroobant V, Colau D, Parmentier N, Boon T, Van den Eynde BJ. Evidence for a tumoral immune resistance mechanism based on tryptophan degradation by indoleamine 2,3dioxygenase. Nat Med. 2003;9(10):1269-74.

123. Muller AJ, DuHadaway JB, Donover PS, Sutanto-Ward E, Prendergast GC. Inhibition of indoleamine 2,3-dioxygenase, an immunoregulatory target of the cancer suppression gene Bin1, potentiates cancer chemotherapy. Nat Med. 2005;11(3):312-9.

124. Nobutani K, Shimono Y, Mizutani K, Ueda Y, Suzuki T, Kitayama M, Minami A, Momose K, Miyawaki K, Akashi K, Azuma T, Takai Y. Downregulation of CXCR4 in Metastasized Breast Cancer Cells and Implication in Their Dormancy. PLoS One. 2015;10(6):e0130032.

125. Zhan Y, Zhang H, Li J, Zhang Y, Zhang J, He L. A novel biphenyl urea derivate inhibits the invasion of breast cancer through the modulation of CXCR4. J Cell Mol Med. 2015;19(7):1614-23.

126. Chalasani SH, Sabelko KA, Sunshine MJ, Littman DR, Raper JA. A chemokine, SDF-1, reduces the effectiveness of multiple axonal repellents and is required for normal axon pathfinding. J Neurosci. 2003;23(4):1360-71.

127. Cimino D, De Pittà C, Orso F, Zampini M, Casara S, Penna E, Quaglino E, Forni M, Damasco C, Pinatel E, Ponzone R, Romualdi C, Brisken C, De Bortoli M, Biglia N, Provero P, Lanfranchi G, Taverna D. miR148b is a major coordinator of breast cancer progression in a relapse-associated microRNA signature by targeting ITGA5, ROCK1, PIK3CA, NRAS, and CSF1. FASEB J. 2013;27(3):1223-35.

128. Cuk K, Zucknick M, Madhavan D, Schott S, Golatta M, Heil J, Marmé F, Turchinovich A, Sinn P, Sohn C, Junkermann H, Schneeweiss A, Burwinkel B. Plasma microRNA panel for minimally invasive detection of breast cancer. PLoS One. 2013;8(10):e76729.

129. Ng EK, Li R, Shin VY, Jin HC, Leung CP, Ma ES, Pang R, Chua D, Chu KM, Law WL, Law SY, Poon RT, Kwong A. Circulating microRNAs as specific biomarkers for breast cancer detection. PLoS One. 2013;8(1):e53141.

130. Chu HW, Cheng CW, Chou WC, Hu LY, Wang HW, Hsiung CN, Hsu HM, Wu PE, Hou MF, Shen CY, Yu JC. A novel estrogen receptor-microRNA 190aPAR-1-pathway regulates breast cancer progression, a finding initially suggested by genome-wide analysis of loci associated with lymph-node metastasis. Hum Mol Genet. 2014;23(2):355-67.

131. Bou Kheir T, Futoma-Kazmierczak E, Jacobsen A, Krogh A, Bardram L, Hother C, Grønbæk K, Federspiel B, Lund AH, Friis-Hansen L. miR-449 inhibits cell proliferation and is down-regulated in gastric cancer. Mol Cancer. 201 1;10.

132. Fils-Aimé N, Dai M, Guo J, El-Mousawi M, Kahramangil B, Neel JC, Lebrun JJ. MicroRNA-584 and the protein phosphatase and actin regulator 1 (PHACTR1), a new Signalling route through which transforming growth factor- $\beta$ Mediates the migration and actin dynamics of breast cancer cells. J Biol Chem. 2013:288(17):11807-23.

133. Berti-Mattera LN, Wilkins PL, Madhun Z, Suchovsky D. P2-purigenic receptors regulate phospholipase $\mathrm{C}$ and adenylate cyclase activities in immortalized Schwann cells. Biochem J. 1996;314(Pt 2):555-61.

134. Di Virgilio F. Purines, purinergic receptors, and cancer. Cancer Res. 2012; 72(21):5441-7.

135. Nass D, Rosenwald S, Meiri E, Gilad S, Tabibian-Keissar H, Schlosberg A Kuker H, Sion-Vardy N, Tobar A, Kharenko O, Sitbon E, Lithwick Yanai G, Elyakim E, Cholakh H, Gibori H, Spector Y, Bentwich Z, Barshack I, Rosenfeld N. MiR-92b and miR-9/9* are specifically expressed in brain primary tumors and can be used to differentiate primary from metastatic brain tumors. Brain Pathol. 2009;19(3):375-83.

136. Zheng ZF, Su HF, Zou Y, Peng Z, Wu SX. Expression profiles of microRNAs in radioresistant esophageal cell line. Zhonghua Yi Xue Za Zhi. 2011;91(9):639-42.

137. Mukhtar RA, Nseyo O, Campbell MJ, Esserman LJ. Tumor-associated macrophages in breast cancer as potential biomarkers for new treatments and diagnostics. Expert Rev Mol Diagn. 2011;11(1):91-100.

138. Hao NB, Lü MH, Fan YH, Cao YL, Zhang ZR, Yang SM. Macrophages in tumor microenvironments and the progression of tumors. Clin Dev Immunol. 2012;2012:948098.

139. Squadrito ML, Pucci F, Magri L, Moi D, Gilfillan GD, Ranghetti A, Casazza A, Mazzone M, Lyle R, Naldini L, De Palma M. miR-511-3p modulates genetic programs of tumor-associated macrophages. Cell Rep. 2012;1(2):141-54. doi: 10.1016/j.celrep.2011.12.005.
140. Karo-Atar D, Itan M, Pasmanik-Chor M, Munitz A. MicroRNA profiling reveals opposing expression patterns for miR-511 in alternatively and classically activated macrophages. J Asthma. 2015;52(6):545-53. doi:10.3109/02770903. 2014.988222.

141. Chen YJ, Zhang X, Wu ZS, Wang JJ, Lau AY, Zhu T, Lobie PE. Autocrine human growth hormone stimulates the tumor initiating capacity and metastasis of estrogen receptor-negative mammary carcinoma cells. Cancer Lett. 2015;365(2):182-9.

142. Elzein S, Goodyer CG. Regulation of human growth hormone receptor expression by microRNAs. Mol Endocrinol. 2014;28(9):1448-59.

143. Roth C, Rack B, Muller V, et al. Circulating microRNAs as blood-based markers for patients with primary and metastatic breast cancer. Breast Cancer Res. 2010;12:R90.

144. Sun Y, Wang M, Lin G, et al. Serum microRNA-155 as a potential biomarker to track disease in breast cancer. PLoS One. 2012;7:e47003.

145. Kurebayashi J, Otsuki T, Moriya T, Sonoo H. Hypoxia reduces hormone responsiveness of human breast cancer cells. Jpn J Cancer Res. 2001;92(10): 1093-101.

146. George AL, Rajoria S, Suriano R, Mittleman A, Tiwari RK. Hypoxia and estrogen are functionally equivalent in breast cancer-endothelial cell interdependence. Mol Cancer. 2012;11:80.

147. Chen S, Chen X, Xiu YL, Sun KX, Zong ZH, Zhao Y. microRNA 490-3P enhances the drug-resistance of human ovarian cancer cells. J Ovarian Res. 2014;7:84

148. Xu X, Wu X, Wu S, Jiang Q, Liu H, Chen R, Sun Y. Study on miR-490-5p and miR-363 as novel biomarkers for the diagnosis of colorectal cancer. Zhonghua Wei Chang Wai Ke Za Zhi. 2014;17(1):45-50.

149. Nguyen HT, Li C, Lin Z, et al. The microRNA expression associated with morphogenesis of breast cancer cells in three-dimensional organotypic culture. Oncol Rep. 2012;28:117-26.

150. Tilch E, Seidens T, Cocciardi S, Reid LE, Byrne D, Simpson PT, Vargas AC, Cummings MC, Fox SB, Lakhani SR, Chenevix TG. Mutations in EGFR, BRAF and RAS are rare in triple-negative and basal-like breast cancers from Caucasian women. Breast Cancer Res Treat. 2014;143(2):385-92. doi:10.1007/s10549-013-2798-1.

151. Wang F, Yang Y, Fu Z, Xu N, Chen F, Yin H, Lu X, Shen R, Lu C. Differential DNA methylation status between breast carcinomatous and normal tissues. Biomed Pharmacother. 2014;68(6):699-707. doi:10.1016/j.biopha.2014.07.014.

152. Takeshita T, Yamamoto Y, Yamamoto-lbusuki M, Inao T, Sueta A, Fujiwara S, Omoto $\mathrm{Y}$, Iwase H. Prognostic role of PIK3CA mutations of cell-free DNA in early-stage triple negative breast cancer. Cancer Sci. 2015;106(11):1582-9. doi:10.1111/cas.12813. Epub 2015 Oct 30.

153. Feng X, Li H, Dean M, Wilson HE, Kornaga E, Enwere EK, Tang P, Paterson A, Lees-Miller SP, Magliocco AM, Bebb G. Low ATM protein expression in malignant tumor as well as cancer-associated stroma are independent prognostic factors in a retrospective study of early-stage hormonenegative breast cancer. Breast Cancer Res. 2015;17:65. doi:10.1186/s13058015-0575-2

154. Cizeron-Clairac G, Lallemand F, Vacher S, Lidereau R, Bieche I, Callens C. MiR-190b, the highest up-regulated miRNA in ERa-positive compared to ERa-negative breast tumors, a new biomarker in breast cancers? BMC Cancer. 2015;15:499. doi:10.1186/s12885-015-1505-5.

155. Shimomura A, Shiino S, Kawauchi J, Takizawa S, Sakamoto H, Matsuzaki J, Ono M, Takeshita F, Niida S, Shimizu C, Fujiwara Y, Kinoshita T, Tamura K, Ochiya T. Novel combination of serum microRNA for detecting breast cancer in the early stage. Cancer Sci. 2016;107(3):326-34. doi:10.1111/cas.12880.

156. Hollmén M, Roudnicky F, Karaman S, Detmar M. Characterization of macrophage-cancer cell crosstalk in estrogen receptor positive and triplenegative breast cancer. Sci Rep. 2015:5:9188. doi:10.1038/srep09188.

157. Tastekin D, Tas F, Karabulut S, Duranyildiz D, Serilmez M, Guveli M, Vatansever S. Clinical significance of serum tenascin-C levels in breast cancer. Tumour Biol. 2014;35(7):6619-25. doi:10.1007/s13277-014-1875-3.

158. Cordero F, Ferrero G, Polidoro S, Fiorito G, Campanella G, Sacerdote C, Mattiello A, Masala G, Agnoli C, Frasca G, Panico S, Palli D, Krogh V, Tumino R, Vineis $P$, Naccarati A. Differentially methylated microRNAs in prediagnostic samples of subjects who developed breast cancer in the European Prospective Investigation into Nutrition and Cancer (EPIC-Italy) cohort. Carcinogenesis. 2015;36(10):1144-53. doi:10.1093/carcin/bgv102. 